Supporting Information

\title{
Boesenmaxane Diterpenoids from Boesenbergia maxwellii
}

The S. Moe, ${ }^{\dagger}$ Suppisak Chaturonrutsamee, ${ }^{\ddagger} \|$ Samreang Bunteang, ${ }^{\ddagger}$ Chutima Kuhakarn, ${ }^{\ddagger}$ Samran Prabpai, ${ }^{\ddagger}$ Panida Surawatanawong, ${ }^{\ddagger}$ Arthit Chairoungdua, ${ }^{\perp}$ Kanoknetr Suksen, ${ }^{\perp}$ Radeekorn Akkarawongsapat, ${ }^{\S}$ Jitra Limthongkul ${ }^{\S}$ Chanita Napaswad, ${ }^{\S}$ Narong Nuntasaen,,$\nabla$ Vichai Reutrakul ${ }^{*}$,

†Pharmaceutical Research Laboratory, Biotechnology Research Department, Ministry of Education, Mandalay Division, Kyaukse 05151, Myanmar

Department of Chemistry and Center of Excellence for Innovation in Chemistry (PERCH-CIC),

${ }^{\perp}$ Department of Physiology, and ${ }^{\S}$ Department of Microbiology, Faculty of Science, Mahidol University, Rama VI Road, Bangkok 10400, Thailand

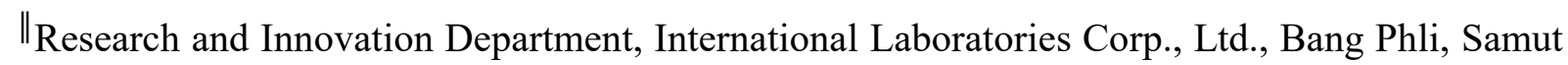
Prakan 10540, Thailand

${ }^{\nabla}$ The Forest Herbarium, National Parks, Wildlife and Plant Conservation Department, Ministry of Natural Resources and Environment, Bangkok 10900, Thailand

\section{* To whom correspondence should be addressed}

Tel: +66 2201 5152. Fax: +66 2644 5126. E-mail: vichai.reu@mahidol.ac.th 
Table of Contents

Page

$\begin{array}{lr}\text { Experimental for Biological Assays } & \text { S4 }\end{array}$

Table S1. Cytotoxic activity of crude extract, fractions and compounds 1-3 $\quad$ S7

Table S2. Anti-HIV-1 RT and syncytium inhibition activities of crude S8 extract, fractions and compounds 1-3

Figure S1. Optimized conformers of $(5 S, 10 S, 12 R)-1$ at the B3LYP/6-31G(d) S9 level in gas phase with populations greater than $1.0 \%$ calculated from their relative Gibbs free energies $(\Delta \mathrm{G})$

Table S3. Important thermodynamic parameters and conformational analysis of $(5 S, 10 S, 12 R)-1$ at the $\mathrm{B} 3 \mathrm{LYP} / 6-31 \mathrm{G}(\mathrm{d})$ level in gas phase, assuming Boltzmann statistics at $\mathrm{T}=298.15 \mathrm{~K}$ and $1 \mathrm{~atm}$

Table S4. Optimized cartesian coordinates of $(5 S, 10 S, 12 R)-1$ at $\mathrm{S} 10$ B3LYP/6-31G(d) level in the gas phase

Table S5. NOEDIFF data of compounds 1-3 (400 MHz, $\left.\mathrm{CDCl}_{3}\right) \quad \mathrm{S} 12$

Figure S2. ${ }^{1} \mathrm{H}$ NMR spectrum of compound $1\left(500 \mathrm{MHz}, \mathrm{CDCl}_{3}\right) \quad \mathrm{S} 13$

Figure S3. ${ }^{13} \mathrm{C}$ NMR spectrum of compound $1\left(125 \mathrm{MHz}, \mathrm{CDCl}_{3}\right) \quad \mathrm{S} 14$

Figure S4. $\quad{ }^{1} \mathrm{H}-{ }^{1} \mathrm{H}$ COSY data of compound $1\left(500 \mathrm{MHz}, \mathrm{CDCl}_{3}\right) \quad \mathrm{S} 15$

Figure S5. HMQC data of compound $1\left(500 \mathrm{MHz}, \mathrm{CDCl}_{3}\right) \quad \mathrm{S} 16$

$\begin{array}{lll}\text { Figure S6. } \mathrm{HMBC} \text { data of compound } 1\left(500 \mathrm{MHz}, \mathrm{CDCl}_{3}\right) & \mathrm{S} 17\end{array}$

$\begin{array}{lll}\text { Figure S7. } \mathrm{HMBC} \text { data of compound } 1\left(400 \mathrm{MHz}, \mathrm{CDCl}_{3}\right) & \mathrm{S} 18\end{array}$

Figure S8. Expansion of the $\mathrm{HMBC}$ data of compound $1\left(400 \mathrm{MHz}, \mathrm{CDCl}_{3}\right) \quad \mathrm{S} 19$

Figure S9. NOESY data of compound $1\left(500 \mathrm{MHz}, \mathrm{CDCl}_{3}\right) \quad$ S20

$\begin{array}{ll}\text { Figure S10. HRESIMS data of compound } 1 & \text { S21 }\end{array}$

Figure S11. ${ }^{1} \mathrm{H}$ NMR spectrum of compound $2\left(500 \mathrm{MHz}, \mathrm{CDCl}_{3}\right) \quad$ S22

Figure S12. ${ }^{13} \mathrm{C}$ NMR spectrum of compound $2\left(125 \mathrm{MHz}, \mathrm{CDCl}_{3}\right) \quad$ S23

Figure S13. ${ }^{1} \mathrm{H}-{ }^{1} \mathrm{H}$ COSY data of compound $2\left(500 \mathrm{MHz}, \mathrm{CDCl}_{3}\right) \quad$ S24

Figure S14. HMQC data of compound $2\left(500 \mathrm{MHz}^{\left.\mathrm{CDCl}_{3}\right)} \quad \mathrm{S} 25\right.$

Figure S15. HMBC data of compound $2\left(500 \mathrm{MHz}, \mathrm{CDCl}_{3}\right) \quad$ S26

Figure S16. NOESY data of compound $2\left(500 \mathrm{MHz}, \mathrm{CDCl}_{3}\right) \quad \mathrm{S} 27$

$\begin{array}{ll}\text { Figure S17. HRESIMS data of compound } 2 & \text { S28 }\end{array}$

Figure S18. ${ }^{1} \mathrm{H}$ NMR spectrum of compound $3\left(500 \mathrm{MHz}, \mathrm{CDCl}_{3}\right) \quad$ S29

Figure S19. ${ }^{13} \mathrm{C}$ NMR data of compound $3\left(125 \mathrm{MHz}, \mathrm{CDCl}_{3}\right) \quad \mathrm{S} 30$

Figure S20. ${ }^{1} \mathrm{H}-{ }^{1} \mathrm{H}$ COSY data of compound $3\left(500 \mathrm{MHz}, \mathrm{CDCl}_{3}\right) \quad \mathrm{S} 31$ 
Figure S21. HMQC data of compound $3\left(500 \mathrm{MHz}, \mathrm{CDCl}_{3}\right) \quad$ S32

Figure S22. HSQC data of compound $3\left(400 \mathrm{MHz}, \mathrm{CDCl}_{3}\right) \quad$ S33

Figure S23. HMBC data of compound $3\left(500 \mathrm{MHz}, \mathrm{CDCl}_{3}\right) \quad \mathrm{S} 34$

Figure S24. NOESY data of compound $3\left(500 \mathrm{MHz}, \mathrm{CDCl}_{3}\right) \quad \mathrm{S} 35$

Figure S25. HRESIMS data of compound $3 \quad$ S36 


\section{Experimental for Biological Assays}

Cytotoxicity Assay. The cytotoxic activities of crude extracts and compounds were performed by using the standard in vitro sulforhodamine B (SRB) assay in 96-well microtiter plates. ${ }^{1}$ Ellipticine, a potent cytotoxic plant alkaloid, was used as a positive control. Eight cell lines were employed, including P-388 (murine lymphocytic leukemia cells), KB (human oral nasopharyngal carcinoma cells), HT-29 (human colorectal adenocarcinoma cells), MCF-7 (human breast cancer cells), A549 (human lung carcinoma cells), ASK (rat glioma cells), T24 (transitional-cell human bladder carcinoma), and HEK-293 (human embryonic kidney cells). The potency of cytotoxic activity is expressed as the half maximal inhibitory concentration (IC50).

Anti-HIV-1 Reverse Transcriptase Assay. Samples were prepared by dissolving in DMSO to obtain a concentration of $20 \mathrm{mg} / \mathrm{mL}$ and kept as stock. Tannin was removed from the samples as described. ${ }^{2}$ The inhibitory activity against RT was determined by using EnzChek Reverse Transcriptase Assay Kit (Molecular Probes, USA) according to the manufacturer's instruction. Briefly, the poly(A) ribonucleotide template was mixed with oligo $d(T) 16$ primer (20:1 weight ratio) for 1 hour at room temperature. Then, the mixture was diluted 200 fold with polymerization buffer $(60 \mathrm{mM}$ Tris- $\mathrm{HCl}, 60 \mathrm{mM} \mathrm{KCl}, 8 \mathrm{mM} \mathrm{MgCl} 2,13 \mathrm{mM} \mathrm{DTT}, 100 \mu \mathrm{M}$ dTTP, $\mathrm{pH} 8.1$ ). In each well of a 96 -well plate, $4 \mu \mathrm{L}$ of the template/primer mixture in the polymerization buffer, $0.70 \mathrm{U}$ of reverse transcriptase enzyme (Merck, USA), and the samples (final concentration of $200 \mu \mathrm{g} / \mathrm{mL}$ ) were mixed and incubated at $37{ }^{\circ} \mathrm{C}$ for 1 hour. Two $\mu \mathrm{L} /$ well of $200 \mathrm{mM}$ EDTA were added in each well to stop the RT enzyme activity. Then, $200 \mu \mathrm{L}$ of a working solution of PicoGreen dsDNA quantitation reagent (345-fold dilution of the provided stock) was added. The plate was further incubated at room temperature for 5 minutes in the dark and taken to a microplate reader (Tecan $\operatorname{Spark}^{\mathrm{TM}} 10 \mathrm{M}$, Switzerland) for fluorescence 
measurement with the excitation and emission wavelengths of 485 and $535 \mathrm{~nm}$, respectively. Nevirapine, a known RT inhibitor, was used as a positive control. The experiment was done in duplicate. The level of reverse transcriptase activity in the presence of the samples was averaged and percent inhibition compared with the negative control was calculated.

Syncytium Reduction Assay. As described previously, the syncytium reduction assay was carried out using the ${ }^{\Delta \text { tat/rev }}$ MC99 virus and $1 \mathrm{~A} 2$ cell line system. ${ }^{3,4}$ Briefly, $5 \times 10^{4}$ cells per well of $1 \mathrm{~A} 2$ cell line (Tat/Rev transfected T4 leukemic cell line) prepared in wells of 96-well plates were incubated with various concentrations (ranging from 3.9-250 $\mu \mathrm{g} / \mathrm{mL}$ ) of the tested samples for 1 hour at $37{ }^{\circ} \mathrm{C}$. Then, the cell/sample mixtures were infected with the ${ }^{\Delta \text { tat/rev }}$ MC99 virus (100-200 syncytium formation units per $50 \mu \mathrm{L})$. The syncytia formed were counted after incubation at $37{ }^{\circ} \mathrm{C}$ for three days. The results were expressed as $50 \%$ effective concentration $\left(\mathrm{EC}_{50}\right)$, or concentration that inhibited syncytia formation by $50 \%$. Each data point was done in triplicate. Controls included cells-only control, no-compound control, and no-virus control. A known HIV-1 replication inhibitor, zidovudine (or azidothymidine, AZT), was used as a positive control. By using a colorimetric XTT assay, cytotoxicity of the tested sample was carried out in parallel in duplicate. The result of cytotoxicity was expressed as the concentration that inhibited formazan formation in uninfected cells by $50 \%\left(\mathrm{IC}_{50}\right)$. The selectivity index (SI) was calculated using the equation $\mathrm{SI}=\mathrm{IC}_{50} / \mathrm{EC}_{50}$.

Anti-microbial Assay. A Gram-negative bacterium (E. coli), three Gram-positive bacteria (S. aureus, E. faecalis, and B. cereus) and a fungal strain (C. albicans) were used as the tested microorganisms for this experiment. Kirby-Bauer disk diffusion method was employed for antimicrobial activity evaluation by modifying the method described by Hudzicki. ${ }^{5}$ Tested samples were dissolved in appropriate solvent to get the concentration of $10 \mathrm{mg} / \mathrm{mL}$. Sterilized 
filter paper disk of $6 \mathrm{~mm}$ in diameter were impregnated with $10 \mu \mathrm{L}$ of dissolved samples to get the final concentration of $100 \mu \mathrm{g} /$ disk. Then the disks were left to dry under the fume hood for overnight. Tested microorganisms were inoculated in Muller Hinton Broth at $37{ }^{\circ} \mathrm{C}$ for overnight. The overnight broth culture was then diluted with normal saline to obtain the OD600 at 0.08 to 0.1 with the approximate cell density of $1.5 \times 10^{8} \mathrm{CFU} / \mathrm{mL}$. Muller Hinton agar plates were prepared and sterilized by autoclaving at $121{ }^{\circ} \mathrm{C}$ for $15 \mathrm{~min}$. The broth inoculums were evenly spread out with sterile cotton swabs on the Muller Hinton agar plates to obtain the uniform inoculums. After the plate was inoculated, prepared filter disks were placed aseptically on the plates. Tetracycline hydrochloride was used as positive control. The plates were then incubated at $37{ }^{\circ} \mathrm{C}$ for 16 to 18 hours and zone diameter of inhibition was recorded and compared with the positive control.

\section{REFERENCES}

(1) Skehan, P.; Storeng, R.; Scudiero, D.; Monks, A.; McMahon, J.; Vistica, D.; Warren, J. T.; Bokesch, H.; Kenney, S.; Boyd, M. R. J. Natl. Cancer Inst. 1990, 82, 1107-1112.

(2) Tan, G. T.; Pezzuto, J. M.; Kinghorn, A. D.; Hughes, S. H. J. Nat. Prod. 1991, 54, $143-154$.

(3) Kiser, R.; Makovsky, S.; Terpening, S. J.; Laing, N.; Clanton, D. J. J. Virol. Methods 1996, 58, 99-109.

(4) Nara, P. L.; Hatch, W. C.; Dunlop, N. M.; Robey, W. G.; Arthur, L. O.; Gonda, M. A.; Fischinger, P. J. AIDS Res. Hum. Retrov. 1987, 3, 283-302.

(5) Hudzicki, J. Kirby-Bauer Disk Diffusion Susceptibility Test Protocol, American Society for Microbiology, 2009. 
Table S1. Cytotoxic activity of crude extract, fractions and compounds $\mathbf{1}-\mathbf{3}$

\begin{tabular}{|c|c|c|c|c|c|c|c|c|}
\hline \multirow{2}{*}{ Extracts/Compounds } & \multicolumn{8}{|c|}{ Cytotoxic assay, cell line $\left(\mathrm{IC}_{50}, \mu \mathrm{M}\right)^{\mathrm{a}}$} \\
\hline & P-388 & KB & HT-29 & MCF-7 & A549 & ASK & HEK-293 & $\mathrm{T} 24$ \\
\hline Crude $\mathrm{MeOH}$ Extract & - & - & - & - & - & - & - & - \\
\hline Fraction $\mathrm{F}_{1}$ & - & - & - & - & - & - & - & - \\
\hline Fraction $F_{2}$ & - & - & - & - & - & - & - & - \\
\hline Fraction $\mathrm{F}_{3}$ & 8.3 & - & - & - & - & - & - & - \\
\hline Fraction $\mathrm{F}_{4}$ & 9.5 & - & - & - & - & 15.5 & - & - \\
\hline Fraction $F_{5}$ & 8.1 & - & - & - & - & - & 17.0 & - \\
\hline Fraction $\mathrm{F}_{6}$ & 13.4 & - & - & - & - & - & - & - \\
\hline Fraction $\mathrm{F}_{7}$ & - & - & - & - & - & - & - & - \\
\hline Fraction $\mathrm{F}_{8}$ & - & - & - & - & - & - & - & - \\
\hline 1 & 44.8 & - & - & - & - & - & - & ND \\
\hline 2 & - & - & - & - & - & - & - & ND \\
\hline 3 & 19.5 & 20.2 & 42.0 & 22.5 & 34.3 & 33.7 & ND & ND \\
\hline Ellipticine $^{\mathrm{b}}$ & 1.4 & 1.7 & 2.4 & 1.6 & 1.5 & 1.8 & 2.0 & - \\
\hline
\end{tabular}

${ }^{\mathrm{a}}$ Each $\mathrm{IC}_{50}$ value presented in $\mu \mathrm{M}$ for pure compound and $\mu \mathrm{g} / \mathrm{mL}$ for crude extract and fractions was obtained from three independent experiments which were conducted in triplicates. Cytotoxic assay: $\mathrm{IC}_{50}$ less than $50 \mu \mathrm{M}$ is considered active for pure compounds. P-388 = murine lymphocytic leukemia, $\mathrm{KB}$ = human nasopharyngeal carcinoma, HT-29 = human colorectal adenocarcinoma, MCF-7 = human breast cancer, A549 = human lung adenocarcinoma epithelial cell line, ASK = rat glioma, HEK-293= human embryonic kidney cells, T24 = transitional-cell human bladder carcinoma. - = IC50 $>50 \mu \mathrm{M}$ for pure compounds and $\mathrm{IC}_{50}>20 \mu \mathrm{g} / \mathrm{mL}$ for crude extracts.

Ellipticine was used as a positive control for cytotoxicity assay. 
Table S2. Anti-HIV-1 RT and syncytium inhibition activities of crude extract, fractions and compounds $\mathbf{1}-\mathbf{3}$

\begin{tabular}{|c|c|c|c|c|c|c|}
\hline \multirow{2}{*}{ Extracts/Compounds } & \multicolumn{2}{|c|}{ Anti-HIV-1 RT } & \multicolumn{4}{|c|}{$\begin{array}{c}\text { Syncytium inhibition (MC99+1A2) } \\
\text { assayc }^{\text {c }}\end{array}$} \\
\hline & $\%$ Inhibition $^{\mathrm{a}}$ & Activity $^{b}$ & $\begin{array}{c}\mathrm{IC}_{50} \\
(\mu \mathrm{M})^{\mathrm{d}}\end{array}$ & $\begin{array}{c}\mathrm{EC}_{50} \\
(\mu \mathrm{M})^{\mathrm{e}}\end{array}$ & SI & Activity \\
\hline Crude $\mathrm{MeOH}$ Extract & 77.8 & VA & 59.5 & 29.3 & 2.0 & Active \\
\hline Fraction $\mathrm{F}_{3}$ & 51.9 & $\mathrm{M}$ & 20.3 & 9.7 & 2.1 & Active \\
\hline Fraction $\mathrm{F}_{4}$ & 63.3 & M & 20.9 & $<7.8$ & $>2.7$ & Active \\
\hline Fraction $\mathrm{F}_{5}$ & 77.5 & VA & 24.1 & 9.5 & 2.5 & Active \\
\hline Fraction $\mathrm{F}_{6}$ & 82.2 & VA & 24.2 & 9.8 & 1.5 & Active \\
\hline Fraction $\mathrm{F}_{7}$ & 32.5 & W & 211.7 & 108.1 & 2.0 & Active \\
\hline Fraction $\mathrm{F}_{8}$ & 2.2 & I & 209.0 & 102.5 & 2.0 & Active \\
\hline 1 & 60.0 & M & $>397.6$ & 55.2 & $>7.2$ & Active \\
\hline 2 & 58.4 & M & $>380.9$ & $>380.9$ & - & Inactive \\
\hline 3 & 34.6 & W & 53.4 & 27.5 & 2.0 & Active \\
\hline
\end{tabular}

${ }^{a}$ Compounds were prescreened at $200 \mu \mathrm{g} / \mathrm{mL}, \mathrm{VA}=$ very active, $>70 \%$ inhibition; $\mathrm{M}=$ moderately active, $>50-70 \%$ inhibition; $\mathrm{W}=$ weakly active, $30-50 \%$ inhibition; $\mathrm{I}=$ inactive, $<30 \%$ inhibition, averaged from two experiments.

${ }^{\mathrm{b}} \mathrm{IC}_{50}$ was determined on compounds that showed very active in HIV-1 RT assay ( $>70 \%$ inhibition). Fagaronine chloride and nevirapine were used as a positive control; $\mathrm{IC}_{50}$ fagaronine chloride, $26.40 \mu \mathrm{M}$ and nevirapine, $7.62 \mu \mathrm{M}$.

${ }^{\mathrm{c}} \mathrm{IC}_{50}$ and $\mathrm{EC}_{50}$ were reported in $\mu \mathrm{g} / \mathrm{mL}$ for crude extract and fractions. AZT was used as a positive control for syncytium inhibition assay and averaged from two experiments, $\mathrm{EC}_{50}>3.74 \times 10^{-8} \mu \mathrm{M}, \mathrm{IC}_{50}$ $1.37 \times 10^{-8} \mu \mathrm{M}$ and $\mathrm{SI}>2.73$.

${ }^{\mathrm{d}} \mathrm{IC}_{50}=$ dose of compound that inhibited $50 \%$ metabolic activity of uninfected $1 \mathrm{~A} 2$ cells.

${ }^{\mathrm{e}} \mathrm{EC}_{50}=$ dose of compound that reduced by $50 \%$ syncytium formation by ${ }^{\Delta T a t / R e v} \mathrm{MC} 99$ virus in $1 \mathrm{~A} 2$ cells.

${ }^{\mathrm{f}}$ Active $=$ at least one point above $50 \%$ inhibition of syncytium formation and cytotoxicity at that point less than $50 \%, \mathrm{EC}_{50}$ less than $700 \mu \mathrm{M}$ and $\mathrm{SI}\left(\mathrm{IC}_{50} / \mathrm{EC}_{50}>1\right)$; Toxic $=\mathrm{IC}_{50}$ is less than the lowest concentration tested. 
Figure S1. Optimized conformers of $(5 S, 10 S, 12 R)-1$ at the B3LYP/6-31G(d) level in gas phase with populations greater than $1.0 \%$ calculated from their relative Gibbs free energies $(\Delta G)$

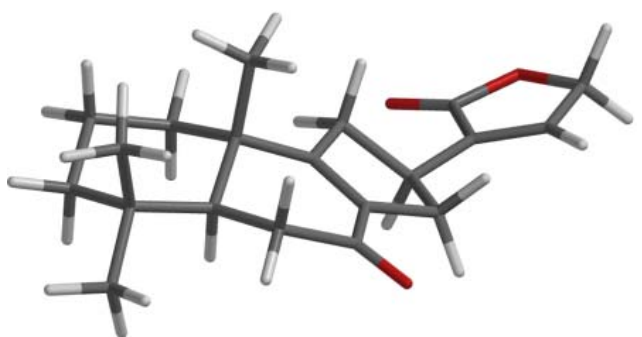

$(5 S, 10 S, 12 R)-\mathbf{1} \mathbf{A}(58.4 \%)$

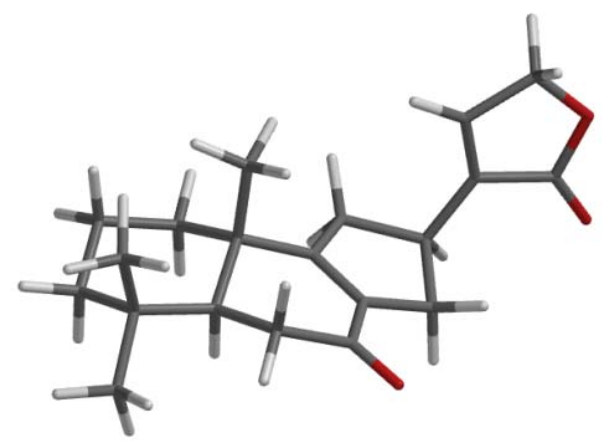

$(5 S, 10 S, 12 R)-1 \mathbf{C}(4.3 \%)$

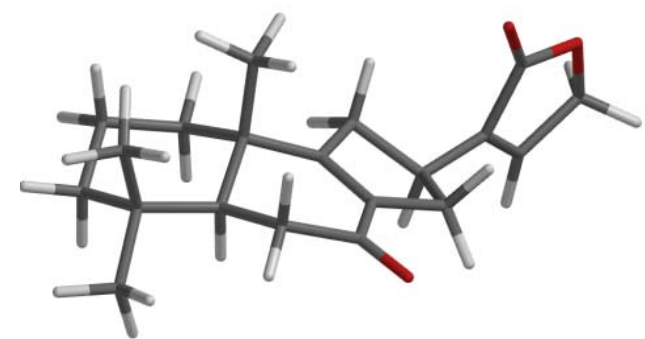

$(5 S, 10 S, 12 R)-1 \mathbf{B}(23.9 \%)$

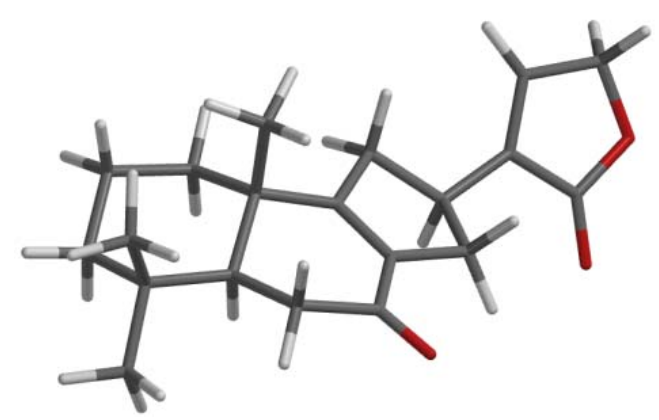

$(5 S, 10 S, 12 R)-1 \mathbf{D}(13.5 \%)$

Table S3. Important thermodynamic parameters and conformational analysis of $(5 S, 10 S, 12 R)-1$ at the B3LYP/6-31G(d) level in gas phase, assuming Boltzmann statistics at $\mathrm{T}=298.15 \mathrm{~K}$ and $1 \mathrm{~atm}^{\mathrm{a}}$

\begin{tabular}{|c|c|c|c|c|c|c|}
\hline Conformers & E (a.u.) & EZPE (a.u.) & H $298 K_{\text {(a.u.) }}$ & $\mathbf{G}_{298 K}$ (a.u.) & $\begin{array}{c}\Delta \mathrm{G}_{298 \mathrm{~K}} \\
\text { (kcal/mol) }\end{array}$ & $\begin{array}{l}P_{G} \\
(\%)\end{array}$ \\
\hline$(5 S, 10 S, 12 R)-\mathbf{1 A}$ & -1003.458427 & -1003.032004 & -1003.010029 & -1003.081246 & 0.00 & 58.4 \\
\hline$(5 S, 10 S, 12 R)-\mathbf{1 B}$ & -1003.458578 & -1003.031728 & -1003.009901 & -1003.080404 & 0.53 & 23.9 \\
\hline$(5 S, 10 S, 12 R)-\mathbf{1 C}$ & -1003.455546 & -1003.029207 & -1003.008244 & -1003.079864 & 1.55 & 4.3 \\
\hline$(5 S, 10 S, 12 R)-\mathbf{1 D}$ & -1003.456420 & -1003.030323 & -1003.003814 & -1003.008244 & 0.87 & 13.5 \\
\hline
\end{tabular}

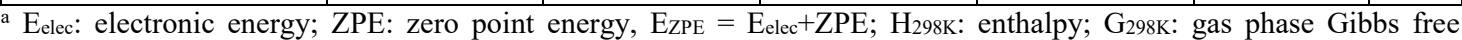
energy; $\Delta \mathrm{G}$ : relative Gibbs free energy at the $\mathrm{B} 3 \mathrm{LYP} / 6-31 \mathrm{G}(\mathrm{d})$ level in gas phase; $\mathrm{P}_{\mathrm{G}}$ : conformational distribution calculated from relative Gibbs free energy. 
Table S4. Optimized cartesian coordinates of $(5 S, 10 S, 12 R)-1$ at B3LYP/6-31G(d) level in the gas phase

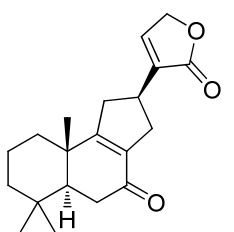

\begin{tabular}{|c|c|c|c|c|c|c|c|c|c|}
\hline \multicolumn{5}{|c|}{$(5 S, 10 S, 12 R)-\mathbf{1 A}$} & \multicolumn{5}{|c|}{$(5 S, 10 S, 12 R)-\mathbf{1} \mathbf{B}$} \\
\hline 1 & $\mathrm{C}$ & 0.038043 & 0.038895 & 0.107551 & 1 & $\mathrm{C}$ & 0.023217 & -0.113215 & -0.075937 \\
\hline 2 & $\mathrm{C}$ & 1.385943 & -0.579422 & 0.443821 & 2 & $\mathrm{C}$ & 1.389472 & -0.680149 & 0.277616 \\
\hline 3 & $\mathrm{C}$ & 3.949289 & -0.224087 & -0.225729 & 3 & $\mathrm{C}$ & 3.954650 & -0.082241 & -0.177763 \\
\hline 4 & $\mathrm{C}$ & 2.907807 & -2.590980 & -0.029267 & 4 & $\mathrm{C}$ & 3.077955 & -2.519966 & -0.316043 \\
\hline 5 & $\mathrm{C}$ & 3.928957 & -1.690018 & -0.732946 & 5 & $\mathrm{C}$ & 4.070704 & -1.478108 & -0.844047 \\
\hline 6 & $\mathrm{C}$ & 1.489220 & -2.015704 & -0.130394 & 6 & $\mathrm{C}$ & 1.630196 & -2.028741 & -0.446567 \\
\hline 7 & $\mathrm{C}$ & 2.478473 & 0.317882 & -0.244800 & 7 & $\mathrm{C}$ & 2.452314 & 0.361584 & -0.230572 \\
\hline 8 & $\mathrm{C}$ & -0.152457 & 1.354384 & -0.136576 & 8 & $\mathrm{C}$ & -0.250486 & 1.206494 & -0.166825 \\
\hline 9 & $\mathrm{C}$ & 2.328397 & 1.792421 & 0.174780 & 9 & $\mathrm{C}$ & 2.172814 & 1.762360 & 0.347000 \\
\hline 10 & $\mathrm{C}$ & 0.930210 & 2.344643 & -0.096196 & 10 & $\mathrm{C}$ & 0.756931 & 2.252719 & 0.049135 \\
\hline 11 & $\mathrm{C}$ & -1.606134 & 1.702144 & -0.351440 & 11 & $\mathrm{C}$ & -1.710859 & 1.481696 & -0.428025 \\
\hline 12 & $\mathrm{C}$ & -1.285160 & -0.697479 & 0.110235 & 12 & $\mathrm{C}$ & -1.241383 & -0.928720 & -0.255103 \\
\hline 13 & $\mathrm{C}$ & -2.250744 & 0.314102 & -0.584668 & 13 & $\mathrm{C}$ & -2.234180 & 0.090208 & -0.894177 \\
\hline 14 & $\mathrm{C}$ & -3.682593 & 0.163420 & -0.175546 & 14 & $\mathrm{C}$ & -3.676552 & -0.167861 & -0.584359 \\
\hline 15 & $\mathrm{C}$ & -4.550881 & 1.015190 & 0.383619 & 15 & $\mathrm{C}$ & -4.715622 & -0.351709 & -1.408493 \\
\hline 16 & $\mathrm{C}$ & -5.874921 & 0.334076 & 0.569241 & 16 & $\mathrm{C}$ & -5.968054 & -0.555615 & -0.609998 \\
\hline 17 & $\mathrm{O}$ & -5.688499 & -0.991597 & 0.062478 & 17 & $\mathrm{O}$ & -5.552204 & -0.476943 & 0.757448 \\
\hline 18 & $\mathrm{C}$ & -4.400234 & -1.127430 & -0.393340 & 18 & $\mathrm{C}$ & -4.199515 & -0.246880 & 0.812924 \\
\hline 19 & $\mathrm{O}$ & -3.985301 & -2.152854 & -0.877527 & 19 & $\mathrm{O}$ & -3.603968 & -0.144117 & 1.858968 \\
\hline 20 & $\mathrm{C}$ & 4.799972 & 0.593864 & -1.224702 & 20 & $\mathrm{C}$ & 4.799543 & 0.899264 & -1.022403 \\
\hline 21 & $\mathrm{C}$ & 4.649076 & -0.138130 & 1.147829 & 21 & $\mathrm{C}$ & 4.567532 & -0.107627 & 1.239166 \\
\hline 22 & $\mathrm{C}$ & 1.453437 & -0.636588 & 1.995663 & 22 & $\mathrm{C}$ & 1.367143 & -0.912586 & 1.814414 \\
\hline 23 & $\mathrm{O}$ & 0.723740 & 3.543153 & -0.244862 & 23 & $\mathrm{O}$ & 0.480044 & 3.445190 & 0.009275 \\
\hline 24 & $\mathrm{H}$ & 2.199934 & 0.283900 & -1.310220 & 24 & $\mathrm{H}$ & 2.238750 & 0.438000 & -1.308775 \\
\hline 25 & $\mathrm{H}$ & -2.197178 & 0.092414 & -1.659816 & 25 & $\mathrm{H}$ & -2.106743 & 0.036023 & -1.982498 \\
\hline 26 & $\mathrm{H}$ & 3.185780 & -2.732986 & 1.022732 & 26 & $\mathrm{H}$ & 3.302539 & -2.767048 & 0.729282 \\
\hline 27 & $\mathrm{H}$ & 2.926642 & -3.590426 & -0.481641 & 27 & $\mathrm{H}$ & 3.196047 & -3.456000 & -0.876655 \\
\hline 28 & $\mathrm{H}$ & 4.937072 & -2.116590 & -0.641680 & 28 & $\mathrm{H}$ & 5.100058 & -1.844917 & -0.732784 \\
\hline 29 & $\mathrm{H}$ & 3.697143 & -1.679171 & -1.808445 & 29 & $\mathrm{H}$ & 3.903238 & -1.358853 & -1.925076 \\
\hline 30 & $\mathrm{H}$ & 0.777981 & -2.675409 & 0.382208 & 30 & $\mathrm{H}$ & 0.938626 & -2.788044 & -0.059958 \\
\hline 31 & $\mathrm{H}$ & 1.191227 & -1.997303 & -1.188654 & 31 & $\mathrm{H}$ & 1.396280 & -1.905581 & -1.514323 \\
\hline 32 & $\mathrm{H}$ & 2.529611 & 1.924580 & 1.247104 & 32 & $\mathrm{H}$ & 2.300818 & 1.776005 & 1.438471 \\
\hline 33 & $\mathrm{H}$ & 3.035171 & 2.441934 & -0.348727 & 33 & $\mathrm{H}$ & 2.860385 & 2.514691 & -0.049041 \\
\hline 34 & $\mathrm{H}$ & -2.008616 & 2.198432 & 0.543872 & 34 & $\mathrm{H}$ & -2.207976 & 1.806394 & 0.494986 \\
\hline 35 & $\mathrm{H}$ & -1.761800 & 2.392881 & -1.186387 & 35 & $\mathrm{H}$ & -1.875857 & 2.264786 & -1.174882 \\
\hline 36 & $\mathrm{H}$ & -1.602072 & -0.901907 & 1.144907 & 36 & $\mathrm{H}$ & -1.609188 & -1.270480 & 0.721938 \\
\hline 37 & $\mathrm{H}$ & -1.269752 & -1.662208 & -0.403177 & 37 & $\mathrm{H}$ & -1.108433 & -1.818632 & -0.879998 \\
\hline 38 & $\mathrm{H}$ & -4.377136 & 2.046650 & 0.668587 & 38 & $\mathrm{H}$ & -4.699407 & -0.355850 & -2.493394 \\
\hline 39 & $\mathrm{H}$ & -6.686246 & 0.815796 & 0.008364 & 39 & $\mathrm{H}$ & -6.433855 & -1.534817 & -0.781070 \\
\hline 40 & $\mathrm{H}$ & -6.181810 & 0.270155 & 1.621280 & 40 & $\mathrm{H}$ & -6.725813 & 0.216912 & -0.794299 \\
\hline 41 & $\mathrm{H}$ & 4.990431 & 1.613414 & -0.872951 & 41 & $\mathrm{H}$ & 4.894159 & 1.881543 & -0.547624 \\
\hline 42 & $\mathrm{H}$ & 4.314974 & 0.659732 & -2.206398 & 42 & $\mathrm{H}$ & 4.367910 & 1.046009 & -2.020125 \\
\hline 43 & $\mathrm{H}$ & 5.775374 & 0.113202 & -1.367498 & 43 & $\mathrm{H}$ & 5.814208 & 0.503969 & -1.153595 \\
\hline 44 & $\mathrm{H}$ & 4.594784 & 0.872342 & 1.568104 & 44 & $\mathrm{H}$ & 4.427467 & 0.847539 & 1.757516 \\
\hline 45 & $\mathrm{H}$ & 5.711981 & -0.384420 & 1.035030 & 45 & $\mathrm{H}$ & 5.648200 & -0.282327 & 1.169145 \\
\hline 46 & $\mathrm{H}$ & 4.236985 & -0.828159 & 1.887567 & 46 & $\mathrm{H}$ & 4.155264 & -0.893610 & 1.875656 \\
\hline 47 & $\mathrm{H}$ & 1.496681 & 0.361804 & 2.440884 & 47 & $\mathrm{H}$ & 1.313341 & 0.029118 & 2.367667 \\
\hline 48 & $\mathrm{H}$ & 0.556040 & -1.130299 & 2.385927 & 48 & $\mathrm{H}$ & 0.482994 & -1.499598 & 2.087427 \\
\hline 49 & $\mathrm{H}$ & 2.313082 & -1.205068 & 2.355510 & 49 & $\mathrm{H}$ & 2.241079 & -1.463715 & 2.166831 \\
\hline
\end{tabular}




\begin{tabular}{|c|c|c|c|c|c|c|c|c|c|}
\hline \multicolumn{5}{|c|}{$(5 S, 10 S, 12 R)-\mathbf{1 C}$} & \multicolumn{5}{|c|}{$(5 S, 10 S, 12 R)-\mathbf{1 D}$} \\
\hline 1 & $\mathrm{C}$ & 0.013977 & -0.173915 & -0.542380 & 1 & $\mathrm{C}$ & 0.103141 & -0.224900 & 0.120120 \\
\hline 2 & $\mathrm{C}$ & 1.348206 & -0.722601 & -0.062588 & 2 & $\mathrm{C}$ & 1.523224 & -0.740806 & 0.295088 \\
\hline 3 & $\mathrm{C}$ & 3.871598 & 0.121583 & 0.187969 & 3 & $\mathrm{C}$ & 4.004236 & 0.060140 & -0.300409 \\
\hline 4 & $\mathrm{C}$ & 3.305667 & -2.249024 & -0.708687 & 4 & $\mathrm{C}$ & 3.247471 & -2.399639 & -0.633072 \\
\hline 5 & $\mathrm{C}$ & 4.264318 & -1.052637 & -0.747518 & 5 & $\mathrm{C}$ & 4.134160 & -1.248971 & -1.122552 \\
\hline 6 & $\mathrm{C}$ & 1.865364 & -1.823469 & -1.023962 & 6 & $\mathrm{C}$ & 1.769933 & -1.988379 & -0.591278 \\
\hline 7 & $\mathrm{C}$ & 2.367952 & 0.473489 & -0.079794 & 7 & $\mathrm{C}$ & 2.481754 & 0.412016 & -0.179594 \\
\hline 8 & $\mathrm{C}$ & -0.372893 & 1.113713 & -0.418230 & 8 & $\mathrm{C}$ & -0.247609 & 1.078043 & 0.189128 \\
\hline 9 & $\mathrm{C}$ & 1.825749 & 1.671468 & 0.723907 & 9 & $\mathrm{C}$ & 2.180188 & 1.722805 & 0.570817 \\
\hline 10 & $\mathrm{C}$ & 0.463231 & 2.142481 & 0.216792 & 10 & $\mathrm{C}$ & 0.719721 & 2.153981 & 0.449342 \\
\hline 11 & $\mathrm{C}$ & -1.742117 & 1.374735 & -0.993528 & 11 & $\mathrm{C}$ & -1.736054 & 1.292478 & 0.067387 \\
\hline 12 & $\mathrm{C}$ & -1.071658 & -0.994368 & -1.207406 & 12 & $\mathrm{C}$ & -1.130867 & -1.094122 & -0.032874 \\
\hline 13 & $\mathrm{C}$ & -2.321271 & -0.066906 & -1.202553 & 13 & $\mathrm{C}$ & -2.222938 & -0.087176 & -0.474773 \\
\hline 14 & $\mathrm{C}$ & -3.311997 & -0.398534 & -0.124539 & 14 & $\mathrm{C}$ & -3.631222 & -0.427033 & -0.100633 \\
\hline 15 & $\mathrm{C}$ & -3.190117 & -0.999711 & 1.065164 & 15 & $\mathrm{C}$ & -4.155894 & -1.360954 & 0.701987 \\
\hline 16 & $\mathrm{C}$ & -4.521770 & -1.019067 & 1.757366 & 16 & $\mathrm{C}$ & -5.651215 & -1.230735 & 0.715872 \\
\hline 17 & $\mathrm{O}$ & -5.423949 & -0.374845 & 0.852584 & 17 & $\mathrm{O}$ & -5.940091 & -0.137701 & -0.160711 \\
\hline 18 & $\mathrm{C}$ & -4.740415 & 0.010001 & -0.275173 & 18 & $\mathrm{C}$ & -4.765267 & 0.361968 & -0.668821 \\
\hline 19 & $\mathrm{O}$ & -5.270270 & 0.572558 & -1.201314 & 19 & $\mathrm{O}$ & -4.729455 & 1.283496 & -1.446352 \\
\hline 20 & $\mathrm{C}$ & 4.748105 & 1.332769 & -0.206697 & 20 & $\mathrm{C}$ & 4.715434 & 1.174318 & -1.103070 \\
\hline 21 & $\mathrm{C}$ & 4.201996 & -0.221223 & 1.656719 & 21 & $\mathrm{C}$ & 4.743510 & -0.071425 & 1.048406 \\
\hline 22 & $\mathrm{C}$ & 1.076806 & -1.342582 & 1.335881 & 22 & $\mathrm{C}$ & 1.652804 & -1.137802 & 1.792411 \\
\hline 23 & $\mathrm{O}$ & 0.086278 & 3.299268 & 0.351762 & 23 & $\mathrm{O}$ & 0.376616 & 3.320794 & 0.587593 \\
\hline 24 & $\mathrm{H}$ & 2.359350 & 0.799133 & -1.132339 & 24 & $\mathrm{H}$ & 2.169159 & 0.588384 & -1.221151 \\
\hline 25 & $\mathrm{H}$ & -2.859885 & -0.115651 & -2.153463 & 25 & $\mathrm{H}$ & -2.189617 & -0.014839 & -1.570156 \\
\hline 26 & $\mathrm{H}$ & 3.351073 & -2.744121 & 0.269509 & 26 & $\mathrm{H}$ & 3.575099 & -2.740019 & 0.357343 \\
\hline 27 & $\mathrm{H}$ & 3.629936 & -3.000956 & -1.439132 & 27 & $\mathrm{H}$ & 3.365406 & -3.262768 & -1.300388 \\
\hline 28 & $\mathrm{H}$ & 5.285106 & -1.378754 & -0.506797 & 28 & $\mathrm{H}$ & 5.186960 & -1.561923 & -1.136908 \\
\hline 29 & $\mathrm{H}$ & 4.299402 & -0.673154 & -1.779612 & 29 & $\mathrm{H}$ & 3.866018 & -1.027809 & -2.166491 \\
\hline 30 & $\mathrm{H}$ & 1.197434 & -2.693851 & -0.991851 & 30 & $\mathrm{H}$ & 1.156478 & -2.826336 & -0.236040 \\
\hline 31 & $\mathrm{H}$ & 1.830638 & -1.439792 & -2.053733 & 31 & $\mathrm{H}$ & 1.436715 & -1.767572 & -1.615852 \\
\hline 32 & $\mathrm{H}$ & 1.716327 & 1.422127 & 1.788881 & 32 & $\mathrm{H}$ & 2.403310 & 1.628675 & 1.642788 \\
\hline 33 & $\mathrm{H}$ & 2.496178 & 2.533737 & 0.679971 & 33 & $\mathrm{H}$ & 2.788946 & 2.554397 & 0.205863 \\
\hline 34 & $\mathrm{H}$ & -2.362961 & 1.994691 & -0.339315 & 34 & $\mathrm{H}$ & -2.173661 & 1.517947 & 1.050263 \\
\hline 35 & $\mathrm{H}$ & -1.670216 & 1.912495 & -1.947918 & 35 & $\mathrm{H}$ & -2.008449 & 2.119155 & -0.593411 \\
\hline 36 & $\mathrm{H}$ & -1.259020 & -1.953536 & -0.708443 & 36 & $\mathrm{H}$ & -1.375172 & -1.560288 & 0.934951 \\
\hline 37 & $\mathrm{H}$ & -0.776632 & -1.246372 & -2.236285 & 37 & $\mathrm{H}$ & -1.008958 & -1.914511 & -0.748356 \\
\hline 38 & $\mathrm{H}$ & -2.294296 & -1.418510 & 1.510071 & 38 & $\mathrm{H}$ & -3.630887 & -2.119134 & 1.272284 \\
\hline 39 & $\mathrm{H}$ & -4.518452 & -0.467849 & 2.706741 & 39 & $\mathrm{H}$ & -6.052418 & -1.001925 & 1.711833 \\
\hline 40 & $\mathrm{H}$ & -4.888078 & -2.034607 & 1.956464 & 40 & $\mathrm{H}$ & -6.162962 & -2.127429 & 0.342710 \\
\hline 41 & $\mathrm{H}$ & 4.641096 & 2.169611 & 0.491622 & 41 & $\mathrm{H}$ & 4.793285 & 2.109578 & -0.538722 \\
\hline 42 & $\mathrm{H}$ & 4.501240 & 1.697203 & -1.211339 & 42 & $\mathrm{H}$ & 4.192708 & 1.389233 & -2.043188 \\
\hline 43 & $\mathrm{H}$ & 5.806507 & 1.045291 & -0.207599 & 43 & $\mathrm{H}$ & 5.736372 & 0.862116 & -1.354314 \\
\hline 44 & $\mathrm{H}$ & 3.838199 & 0.551439 & 2.343165 & 44 & $\mathrm{H}$ & 4.601594 & 0.816874 & 1.673917 \\
\hline 45 & $\mathrm{H}$ & 5.289556 & -0.282681 & 1.784390 & 45 & $\mathrm{H}$ & 5.820784 & -0.172355 & 0.868486 \\
\hline 46 & $\mathrm{H}$ & 3.786777 & -1.177570 & 1.982565 & 46 & $\mathrm{H}$ & 4.432382 & -0.941177 & 1.631500 \\
\hline 47 & $\mathrm{H}$ & 0.809066 & -0.582081 & 2.075425 & 47 & $\mathrm{H}$ & 1.596798 & -0.267703 & 2.453058 \\
\hline 48 & $\mathrm{H}$ & 0.239050 & -2.047646 & 1.270348 & 48 & $\mathrm{H}$ & 0.832291 & -1.810465 & 2.068731 \\
\hline 49 & $\mathrm{H}$ & 1.931745 & -1.901644 & 1.719967 & 49 & $\mathrm{H}$ & 2.584200 & -1.665651 & 2.006108 \\
\hline
\end{tabular}


Table S5. NOEDIFF data of compounds $\mathbf{1}-\mathbf{3}\left(400 \mathrm{MHz}, \mathrm{CDCl}_{3}\right)$

\begin{tabular}{|c|c|c|c|}
\hline $\mathrm{H}$ & 1 & 2 & 3 \\
\hline $\mathrm{H}-1_{\mathrm{ax}}$ & H-2 eq, H-5, H-11 eq & H-2 eq, H-5, H-1 $1_{\text {eq }}$ & \\
\hline \multirow[t]{2}{*}{$\mathrm{H}-1_{\mathrm{eq}}$} & & H-2 eq, H-11 $1_{\mathrm{eq}}, \mathrm{H}-11_{\mathrm{ax}}$ & \\
\hline & & Me-20 & \\
\hline $\mathrm{H}-3_{\mathrm{ax}}$ & H-2 eq, H-5, Me-19 & & \\
\hline $\mathrm{H}-5$ & & H- $1_{\text {ax }}, H-6_{\text {eq }}$, Me-19 & \\
\hline$H-6_{a x}$ & & & H-7, Me-18, Me-20 \\
\hline H-1 $1_{\text {eq }}$ & $\mathrm{H}-12$ & & \\
\hline $\mathrm{H}-12$ & H-1 $1_{\text {eq }}, \mathrm{H}-13_{\text {eq }}$ & H-11 eq, H-13 eq, H-15 & \\
\hline $\mathrm{H}-13_{\mathrm{eq}}$ & $\mathrm{H}-12$ & $\mathrm{H}-12$ & \\
\hline \multirow[t]{2}{*}{ Me-20 } & H-1 $1_{\mathrm{eq}}, \mathrm{H}-6_{\mathrm{ax}}, \mathrm{H}-11_{\mathrm{ax}}$, & H- $1_{\text {eq }}, H-2_{\text {ax }}, H-6_{\text {ax }}$, & H-1 $1_{\text {eq }}, H-6_{\text {ax }}, H-11_{\text {ax }}$, \\
\hline & Me-18 & $\mathrm{H}-11_{\mathrm{ax}}, \mathrm{Me}-18$ & Me-18 \\
\hline
\end{tabular}


$\mathrm{C}-1325-5-\mathrm{Rz}-12 \mathrm{~F} 2-\mathrm{C}$ in $\mathrm{CDC} 13$
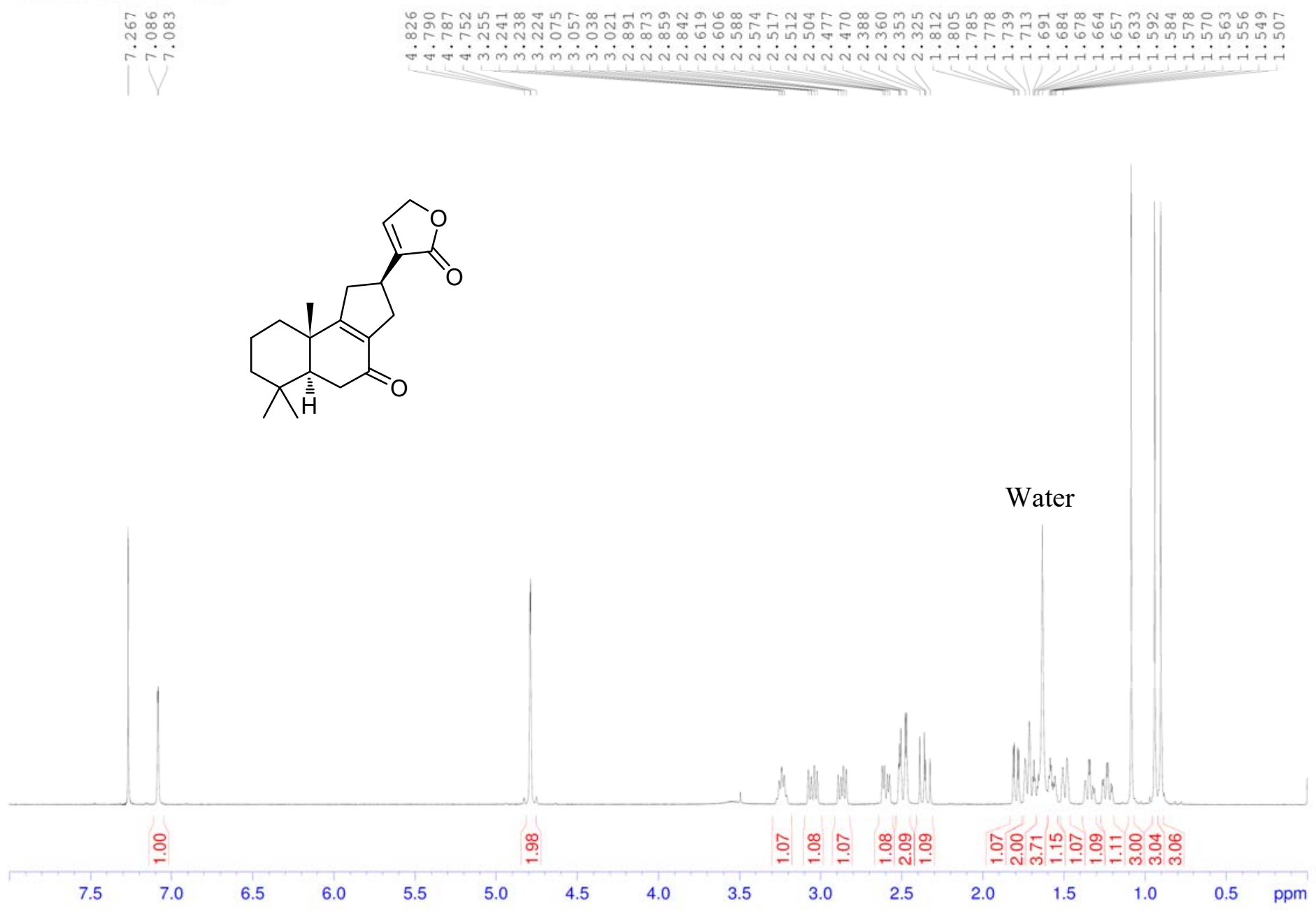

Figure S2. ${ }^{1} \mathrm{H}$ NMR spectrum of compound $1\left(500 \mathrm{MHz}, \mathrm{CDCl}_{3}\right)$ 


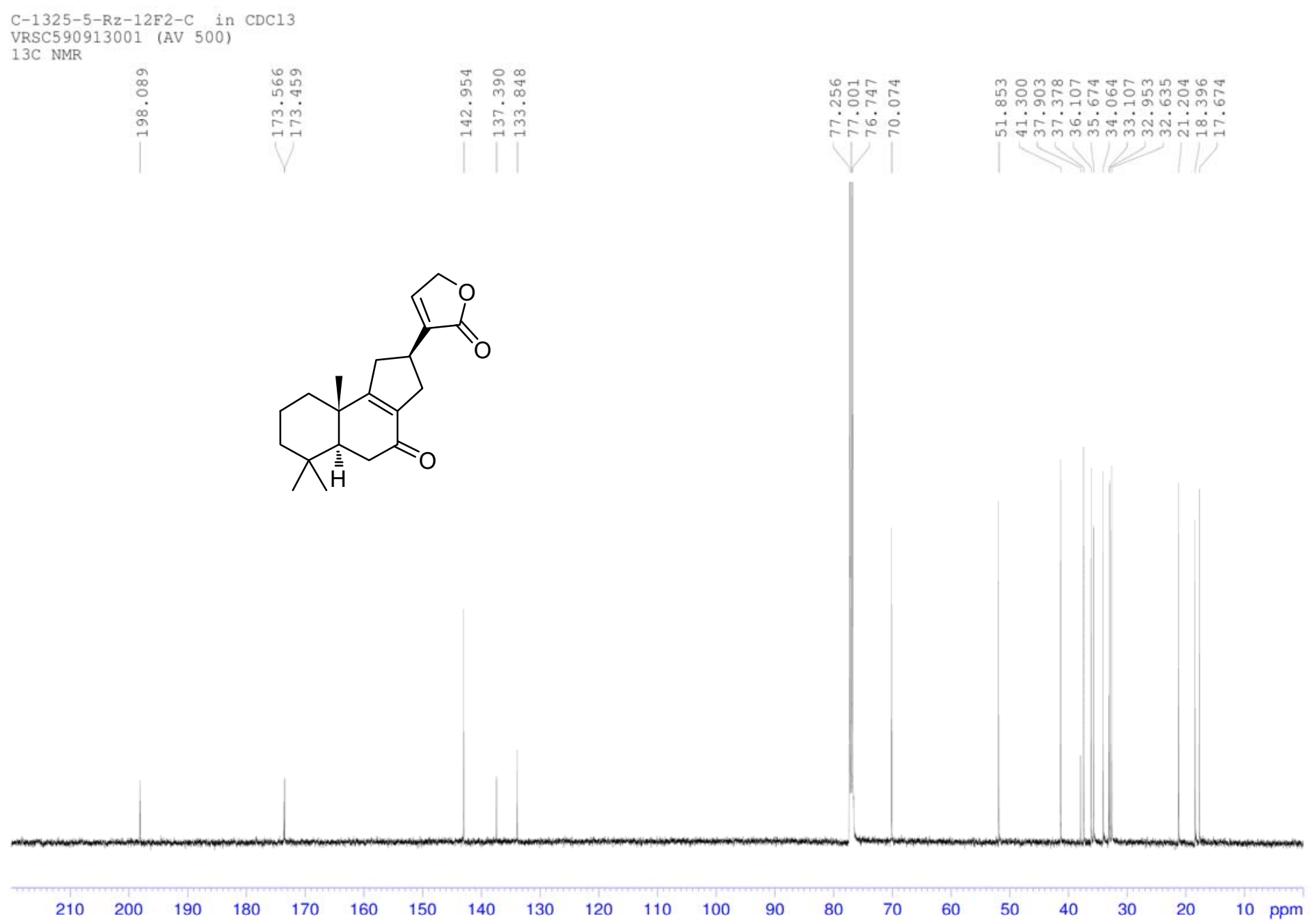

Figure S3. ${ }^{13} \mathrm{C}$ NMR spectrum of compound $1\left(125 \mathrm{MHz}, \mathrm{CDCl}_{3}\right)$ 


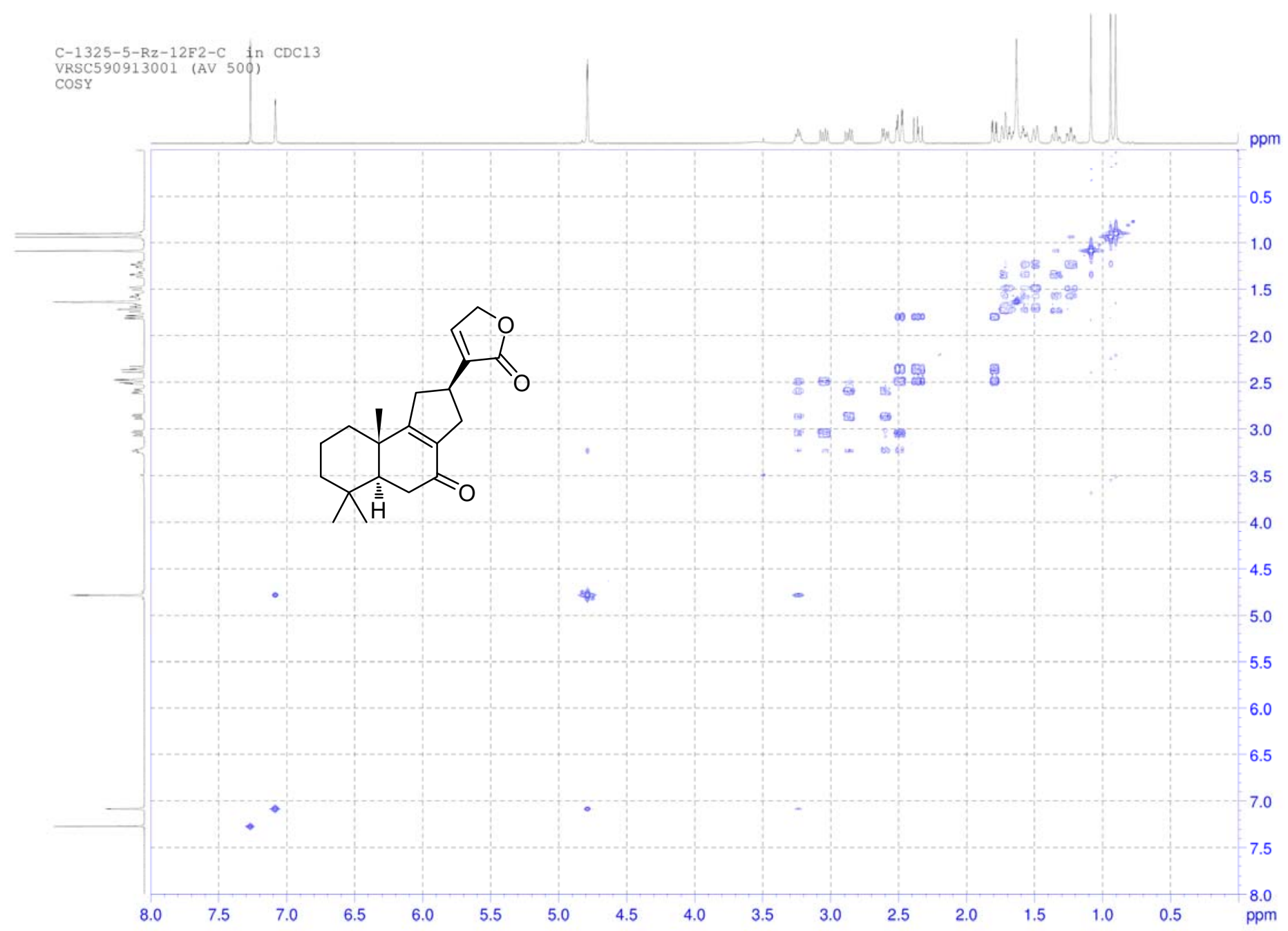

Figure S4. ${ }^{1} \mathrm{H}-{ }^{1} \mathrm{H}$ COSY data of compound $1\left(500 \mathrm{MHz}, \mathrm{CDCl}_{3}\right)$ 


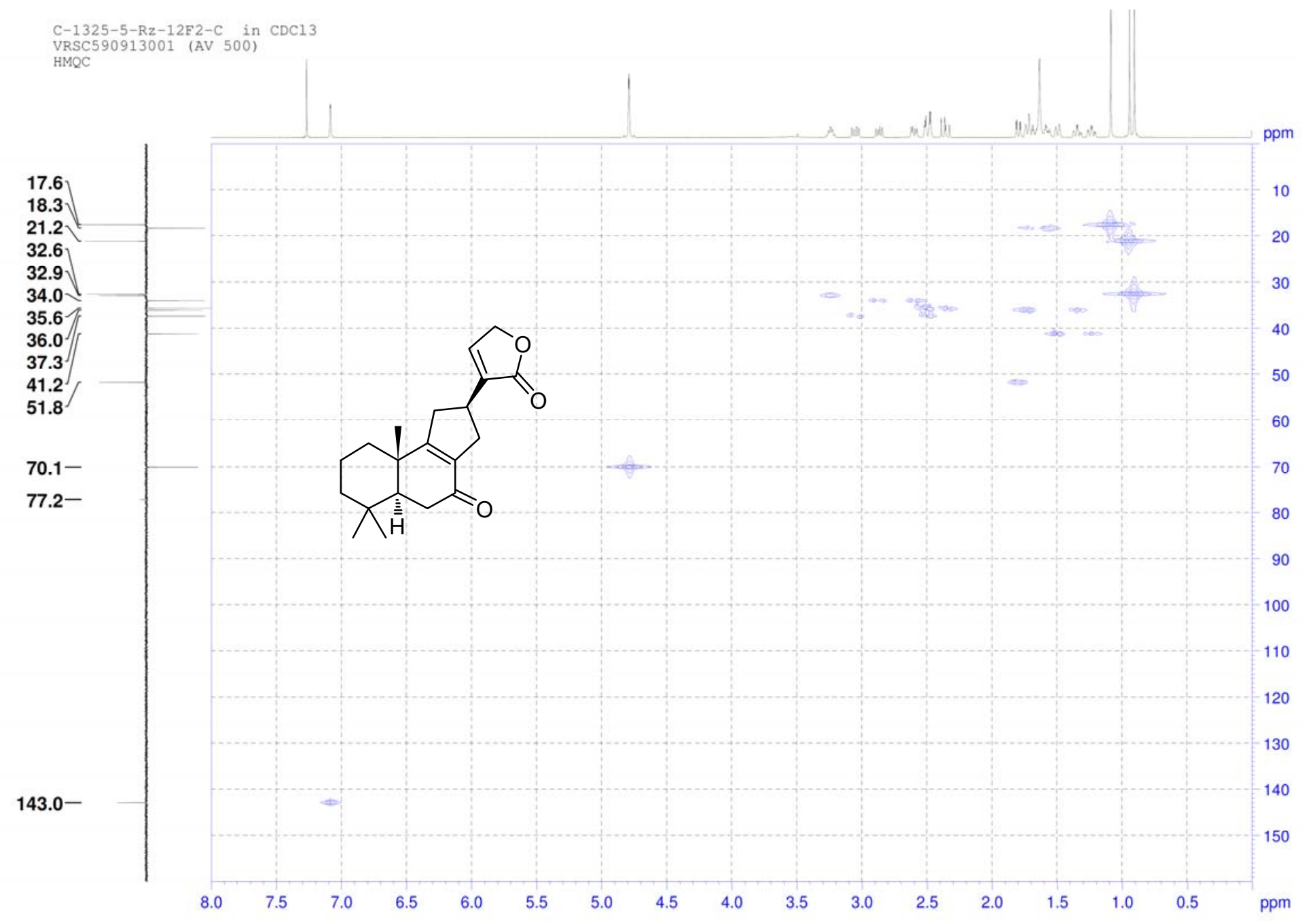

Figure S5. HMQC data of compound $1\left(500 \mathrm{MHz}, \mathrm{CDCl}_{3}\right)$ 


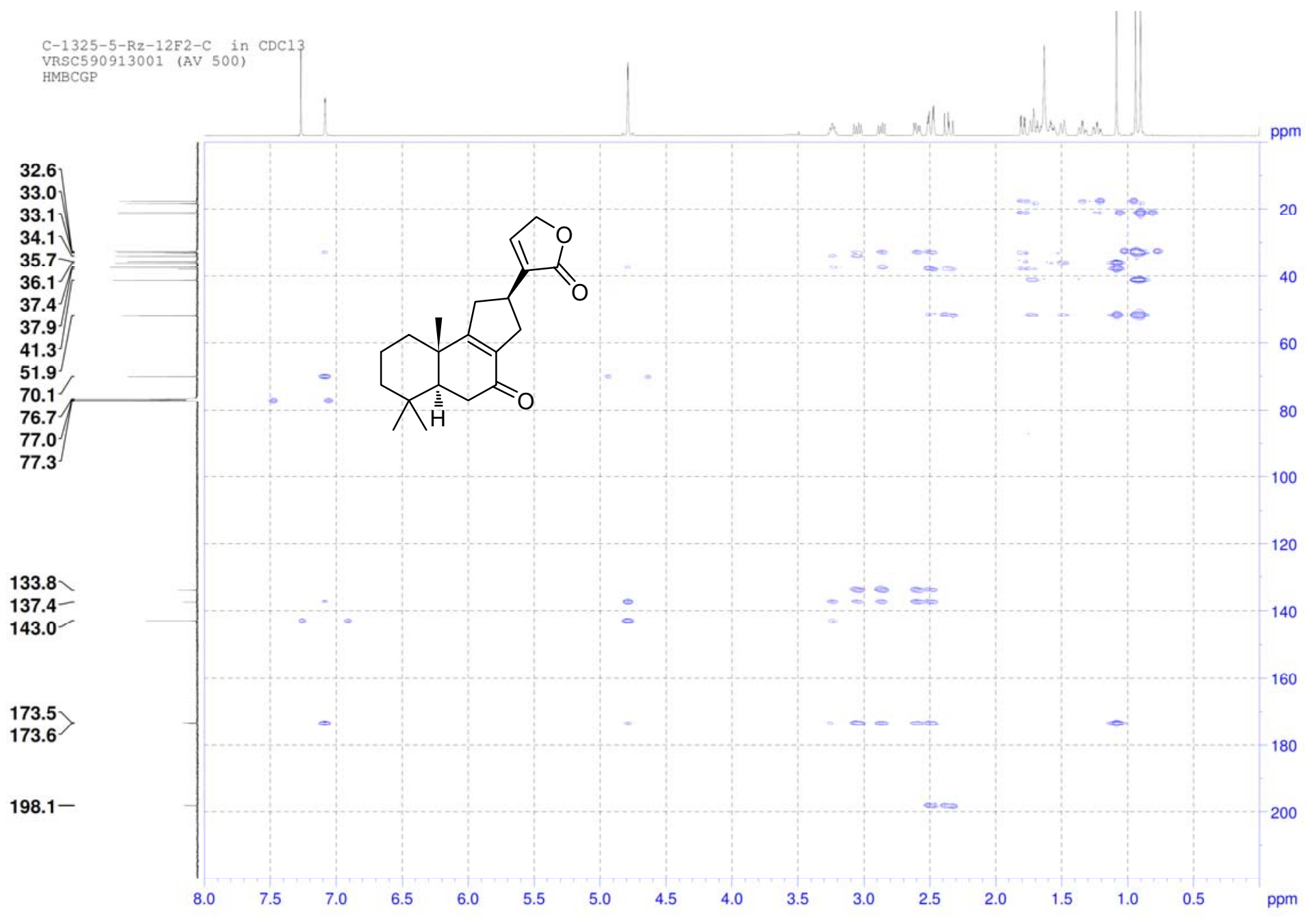

Figure S6. HMBC data of compound $1\left(500 \mathrm{MHz}, \mathrm{CDCl}_{3}\right)$ 


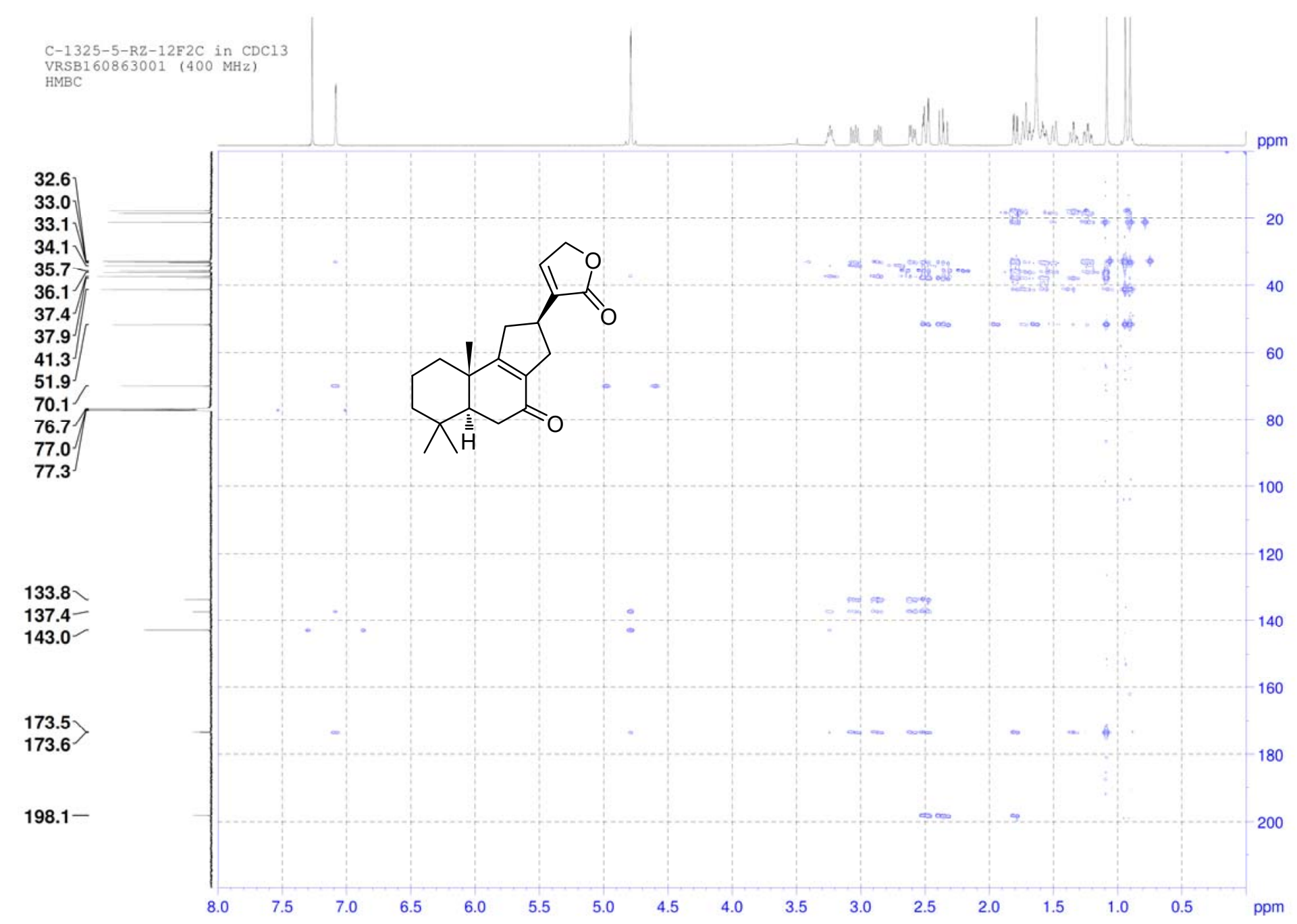

Figure S7. HMBC data of compound $1\left(400 \mathrm{MHz}, \mathrm{CDCl}_{3}\right)$ 


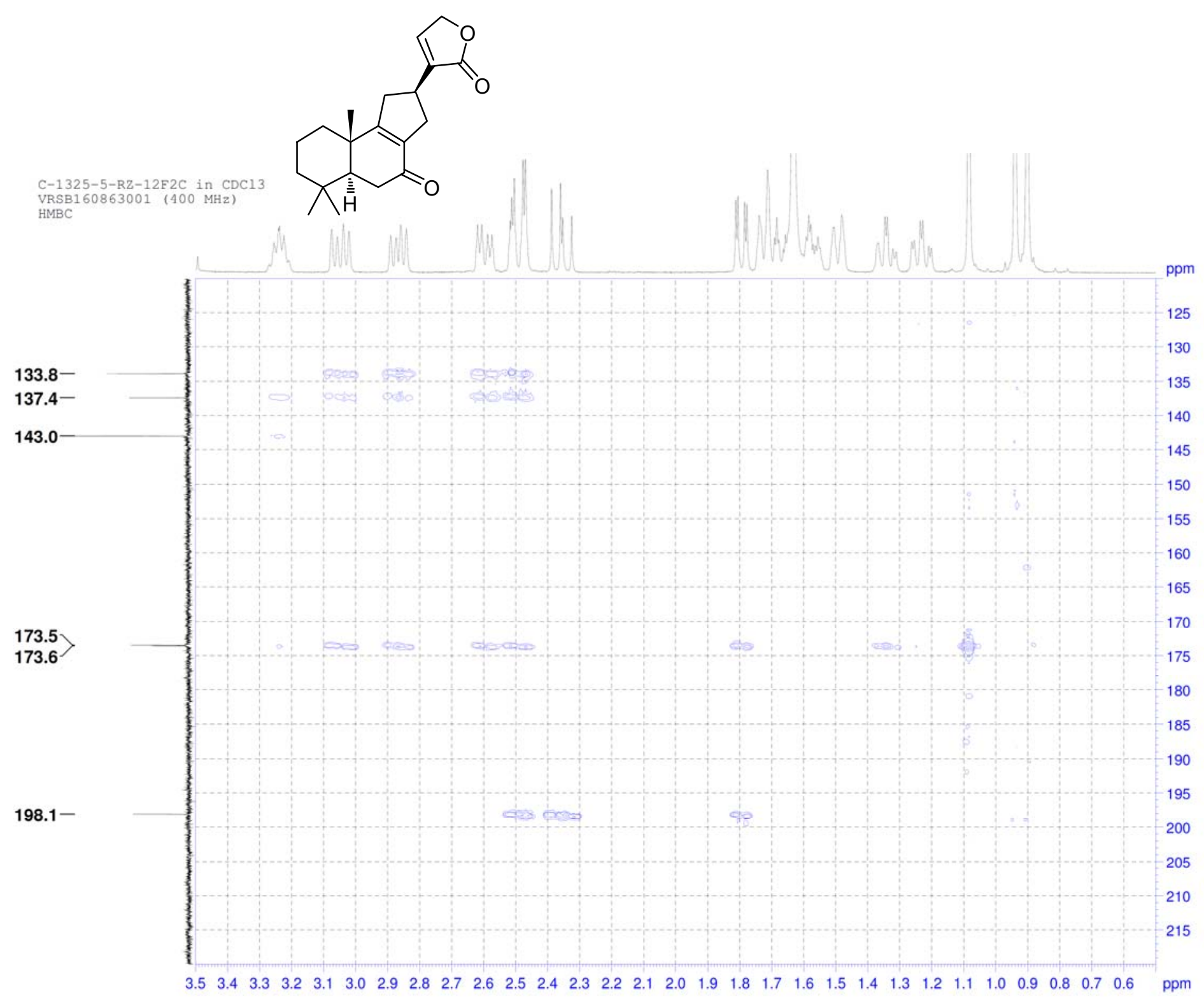

Figure S8. Expansion of the $\mathrm{HMBC}$ data of compound $1\left(400 \mathrm{MHz}, \mathrm{CDCl}_{3}\right)$ 


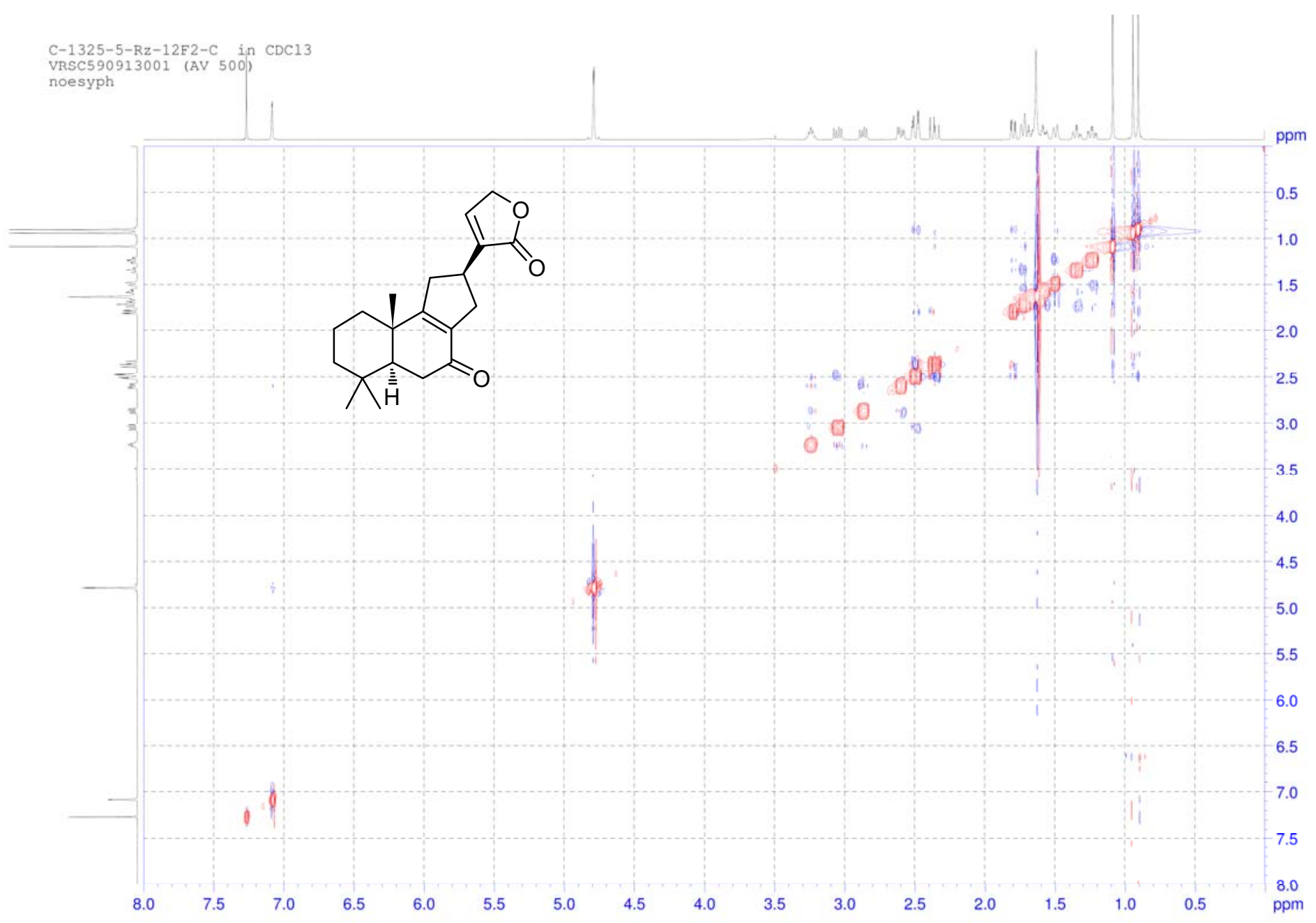

Figure S9. NOESY data of compound $1\left(500 \mathrm{MHz}, \mathrm{CDCl}_{3}\right)$ 


\section{Mass Spectrum List Report}

Analysis Info

Analysis Name VRTSM909013001.d

$\begin{array}{ll}\text { Method } & \text { Tune_low_POS_13_09_16.m } \\ \text { Sample Name } & \text { C-1325-5.Rz-12F2-C }\end{array}$

Sample Name

Acquisition Date

Operator

2/13/2016 2:00:37 PM

13-09-16

Instrument

Administrator

micrOTOF 72

\begin{tabular}{|c|c|c|c|c|c|}
\hline \multicolumn{4}{|c|}{ Acquisition Parameter } & Set Corrector Fill & $50 \mathrm{~V}$ \\
\hline Source Type & ESI & Ion Polarity & Positive & Set Pulsar Pull & $337 \mathrm{~V}$ \\
\hline Scan Range & $\mathrm{n} / \mathrm{a}$ & Capillary Exit & $100.0 \mathrm{~V}$ & Set Pulsar Push & $337 \mathrm{~V}$ \\
\hline Scan Begin & $50 \mathrm{~m} / \mathrm{z}$ & Hexapole RF & $150.0 \mathrm{~V}$ & Set Reflector & $1300 \mathrm{~V}$ \\
\hline Scan End & $3000 \mathrm{~m} / \mathrm{z}$ & Skimmer 1 & $45.0 \mathrm{~V}$ & Set Flight Tube & $\begin{array}{l}9000 \mathrm{~V} \\
2295 \mathrm{~V}\end{array}$ \\
\hline
\end{tabular}

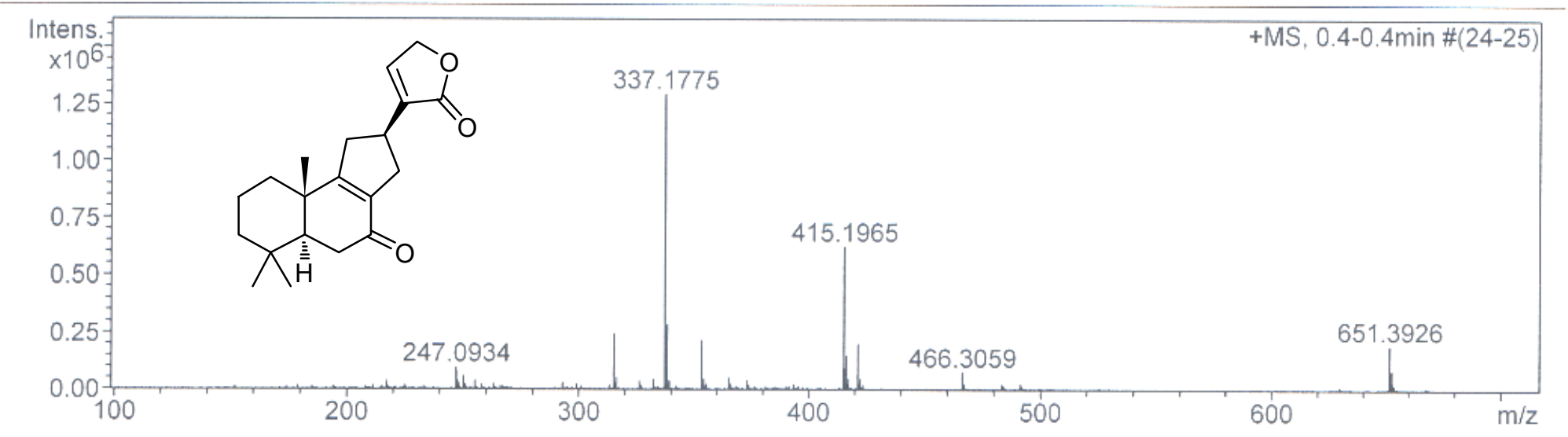

Figure S10. HRESIMS data of compound 1 
C-1325-5-RZ-23F2 in CDC13
VRSC591003001 (AV 500)

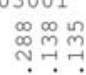

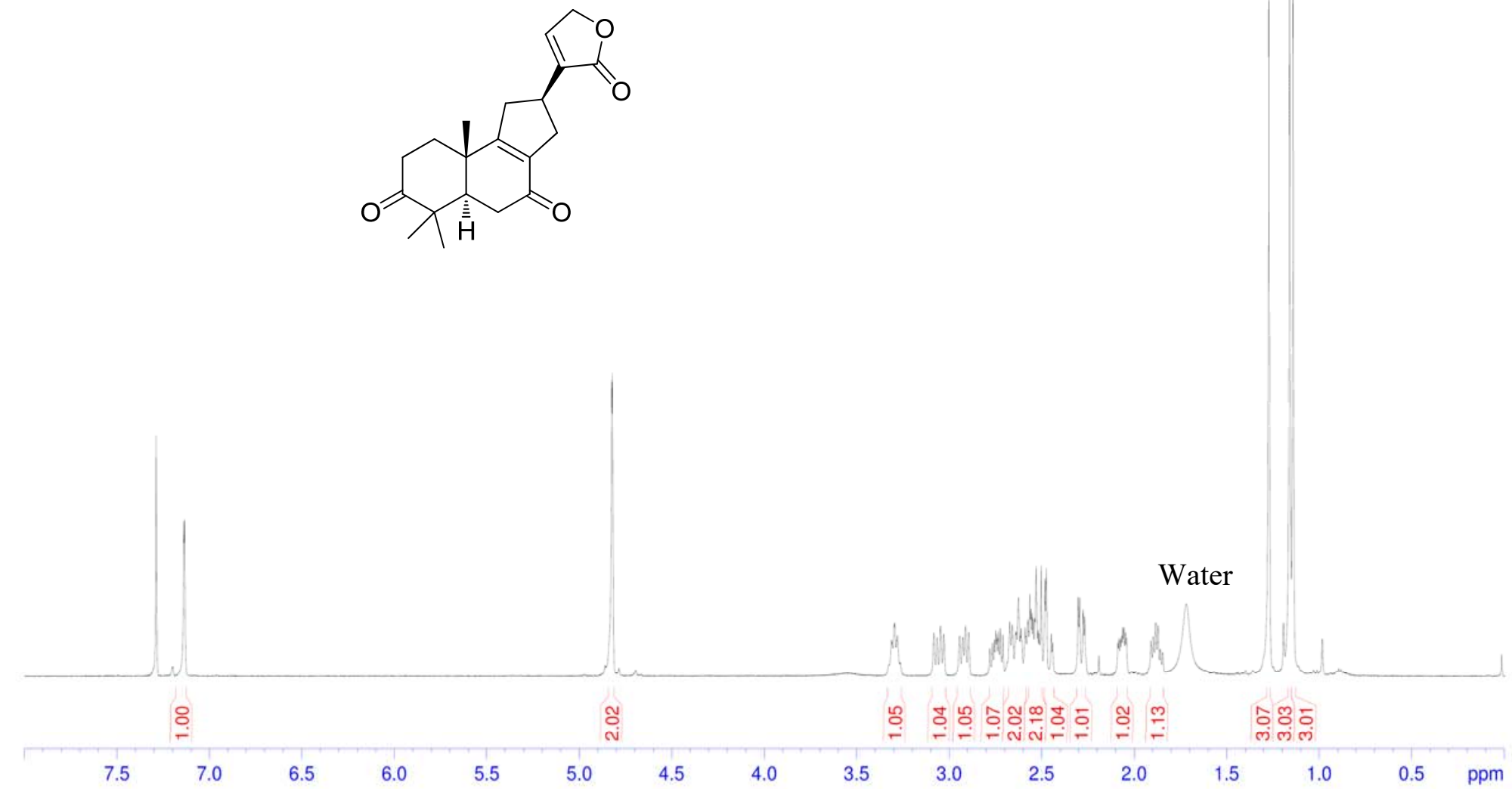

Figure S11. ${ }^{1} \mathrm{H}$ NMR spectrum of compound $2\left(500 \mathrm{MHz}, \mathrm{CDCl}_{3}\right)$ 
C-1325-5-RZ-23F2 in $\mathrm{CDCl}^{3}$

RSC591003001 (AV 500)

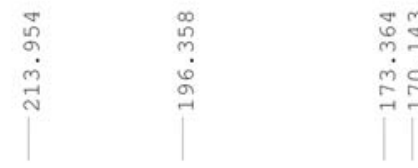

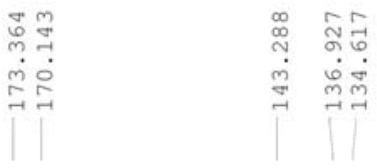

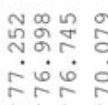

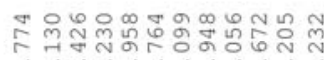

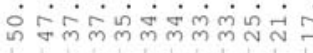

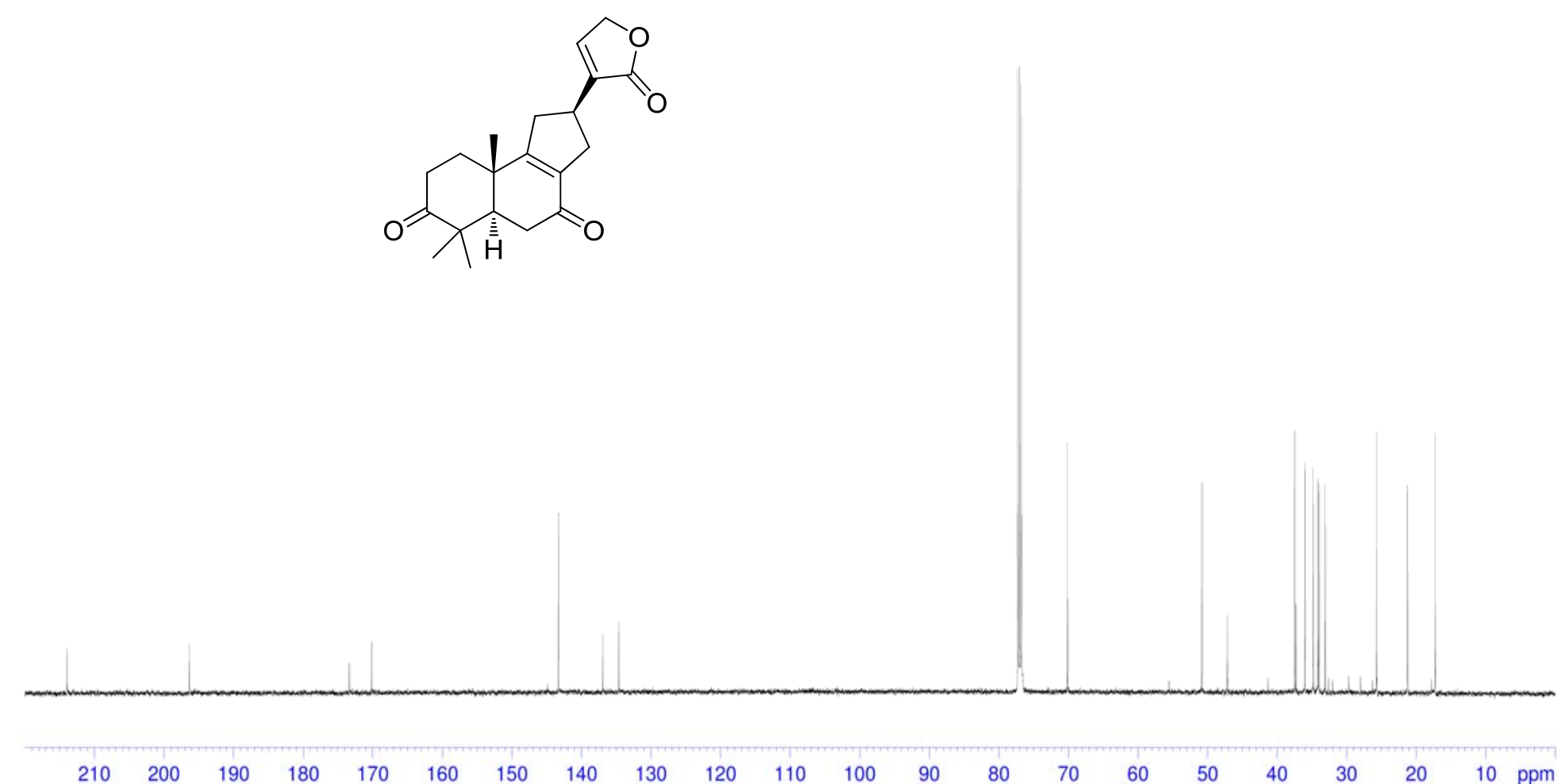

V

$11 / 1$

Figure S12. ${ }^{13} \mathrm{C}$ NMR spectrum of compound $2\left(125 \mathrm{MHz}, \mathrm{CDCl}_{3}\right)$ 


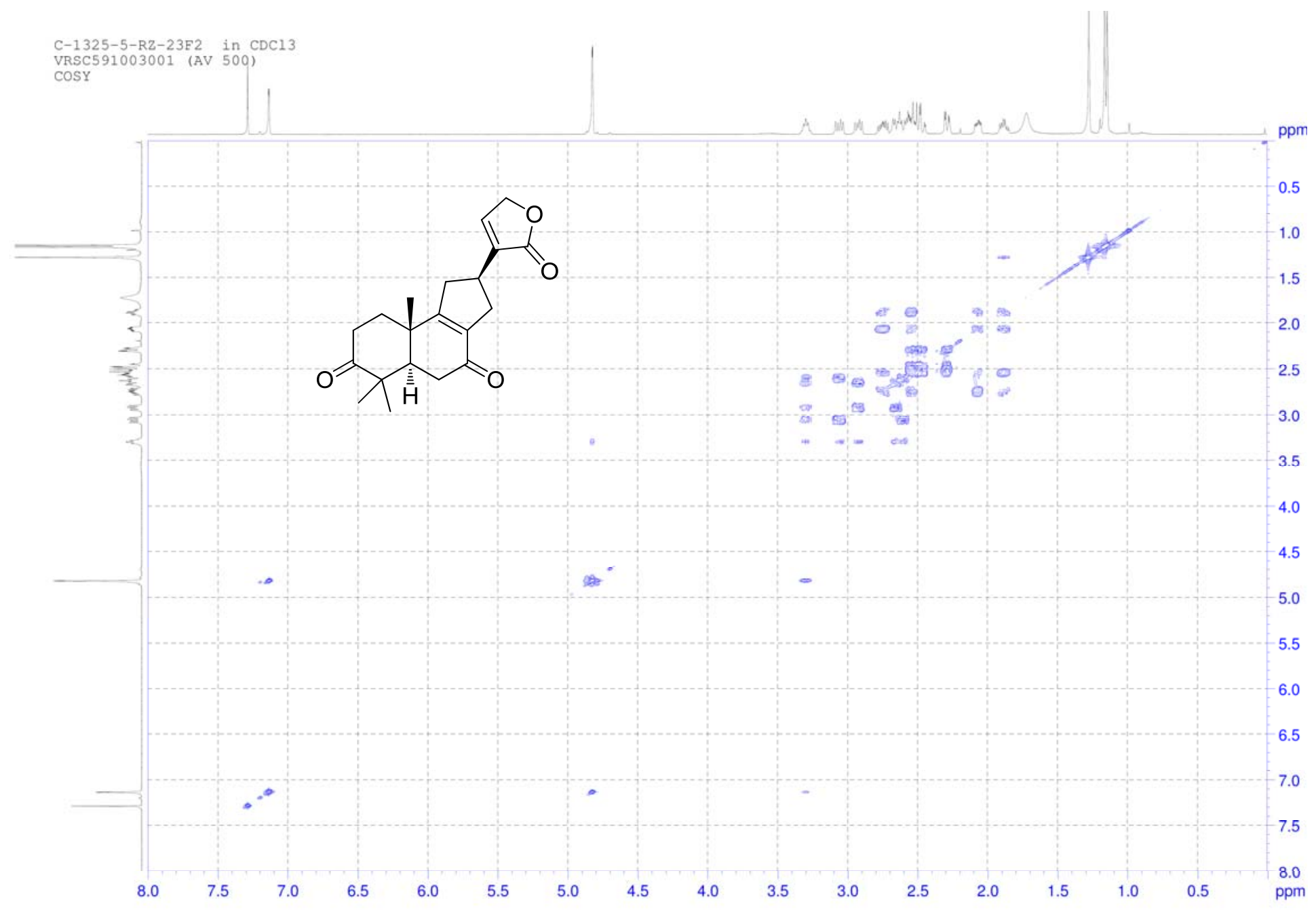

Figure S13. ${ }^{1} \mathrm{H}-{ }^{1} \mathrm{H}$ COSY data of compound $2\left(500 \mathrm{MHz}, \mathrm{CDCl}_{3}\right)$ 


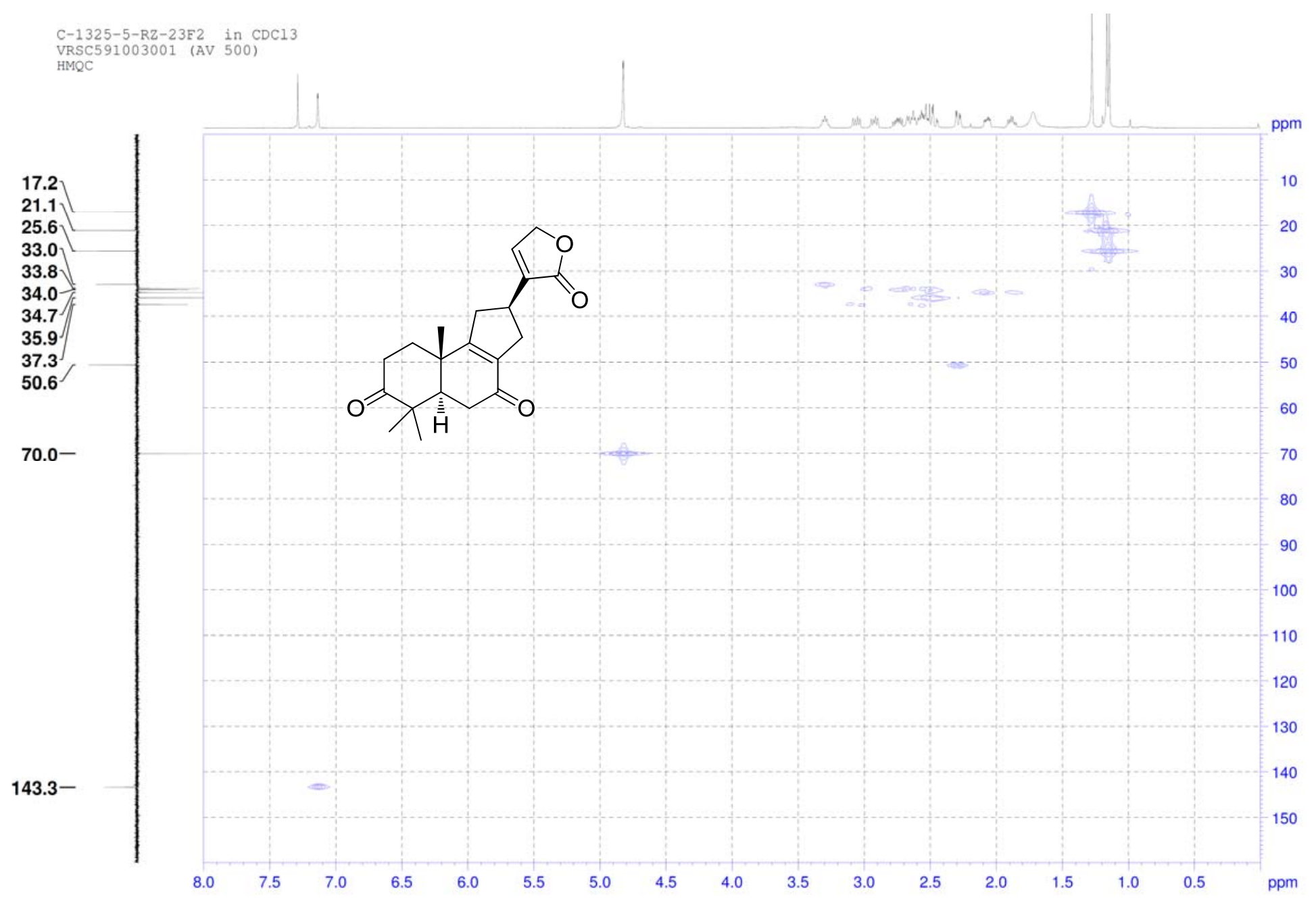

Figure S14. HMQC data of compound $2\left(500 \mathrm{MHz}, \mathrm{CDCl}_{3}\right)$ 


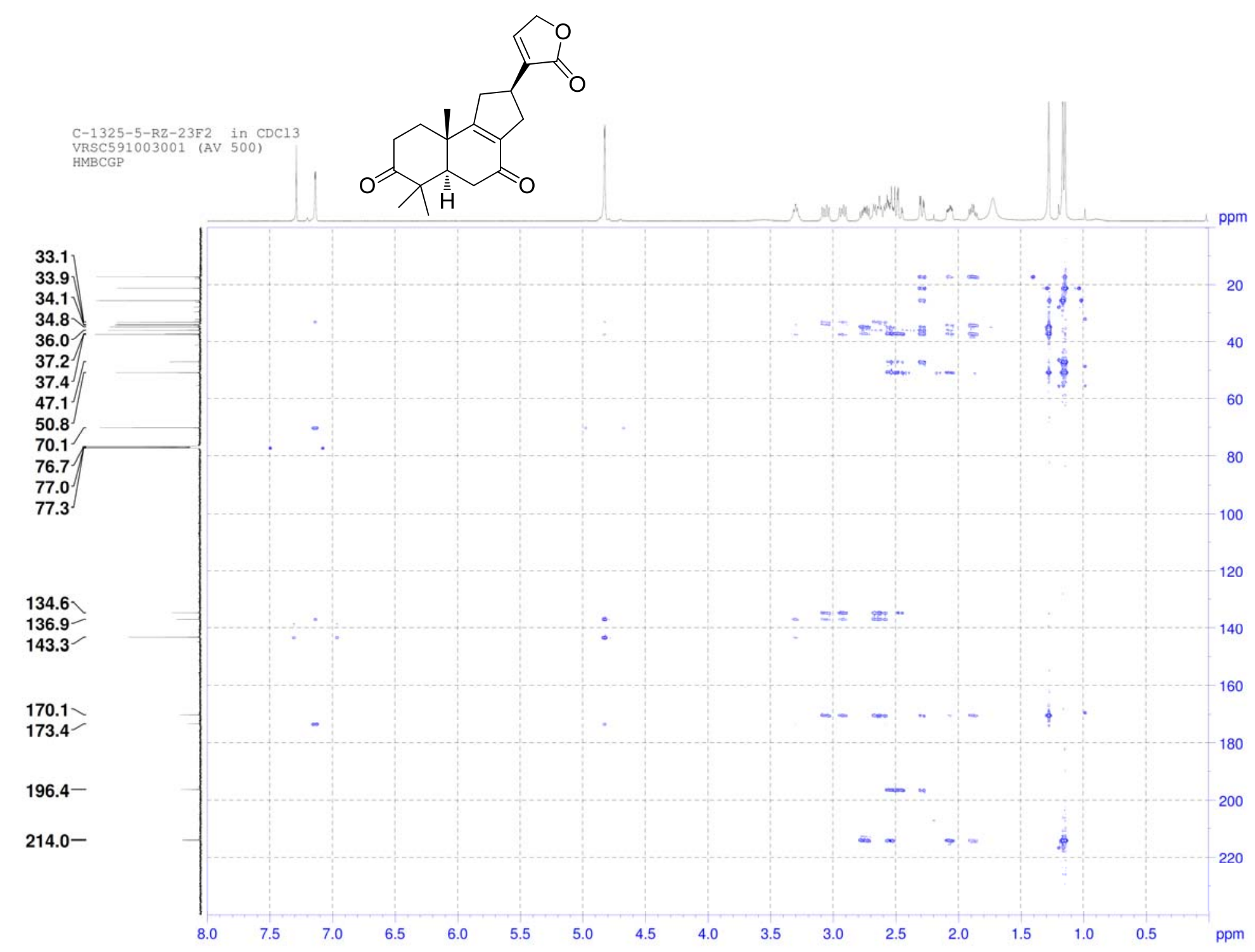

Figure S15. HMBC data of compound $2\left(500 \mathrm{MHz}, \mathrm{CDCl}_{3}\right)$ 


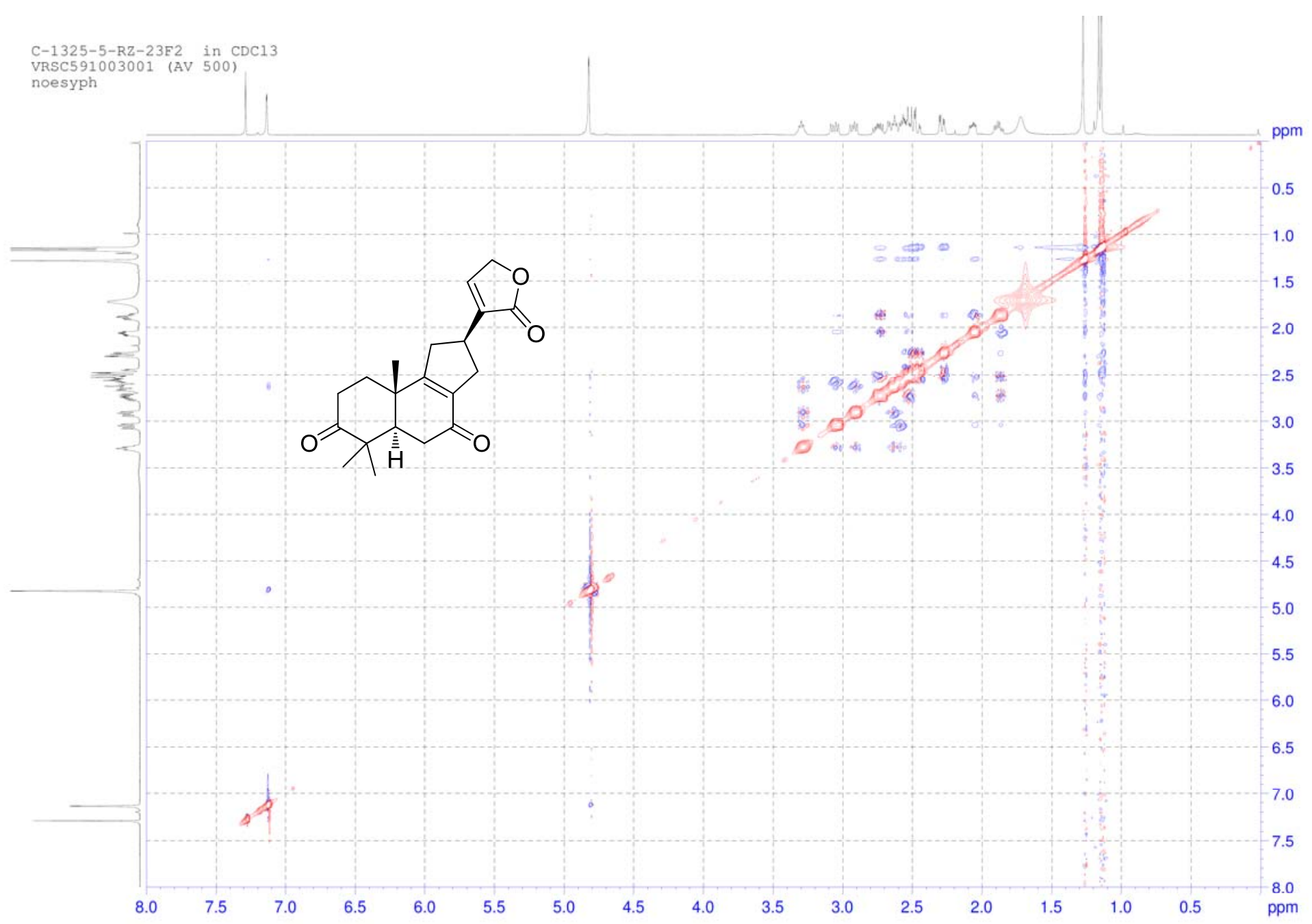

Figure S16. NOESY data of compound $2\left(500 \mathrm{MHz}, \mathrm{CDCl}_{3}\right)$ 


\section{Mass Spectrum List Report}

\section{Analysis Info}

Analysis Name

Method

VRTSM591012001.d

Tune_low_POS_13_09_16.m

C-1325.5.RZ-23F2

Acquisition Date

Operator

10/12/2016 10:33:46 AM

Sample Name

12-10-2016

\section{Acquisition Parameter}

Source Type ESI

Scan Range

ESI

Scan Begin

$\mathrm{n} / \mathrm{a}$

$50 \mathrm{~m} / \mathrm{z}$

Scan End

$3000 \mathrm{~m} / \mathrm{z}$

$\begin{array}{ll}\text { Ion Polarity } & \text { Positive } \\ \text { Capillary Exit } & 180.0 \mathrm{~V} \\ \text { Hexapole RF } & 150.0 \mathrm{~V} \\ \text { Skimmer 1 } & 45.0 \mathrm{~V} \\ \text { Hexapole } 1 & 24.3 \mathrm{~V}\end{array}$

Set Corrector Fill

Set Pulsar Pull

Administrato

micrOTOF

72

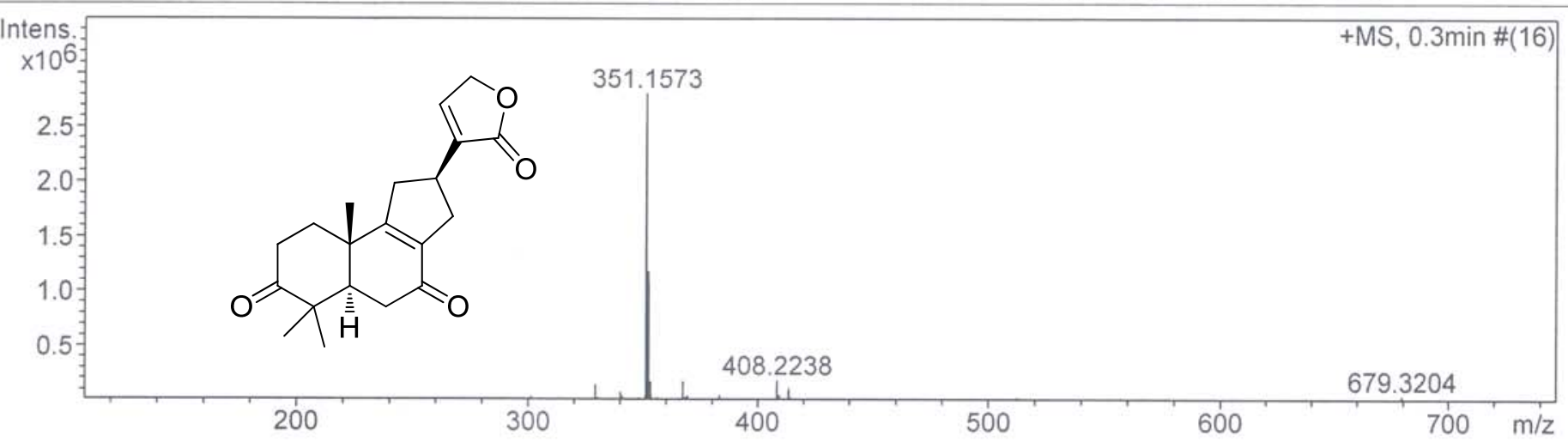

Figure S17. HRESIMS data of compound 2 

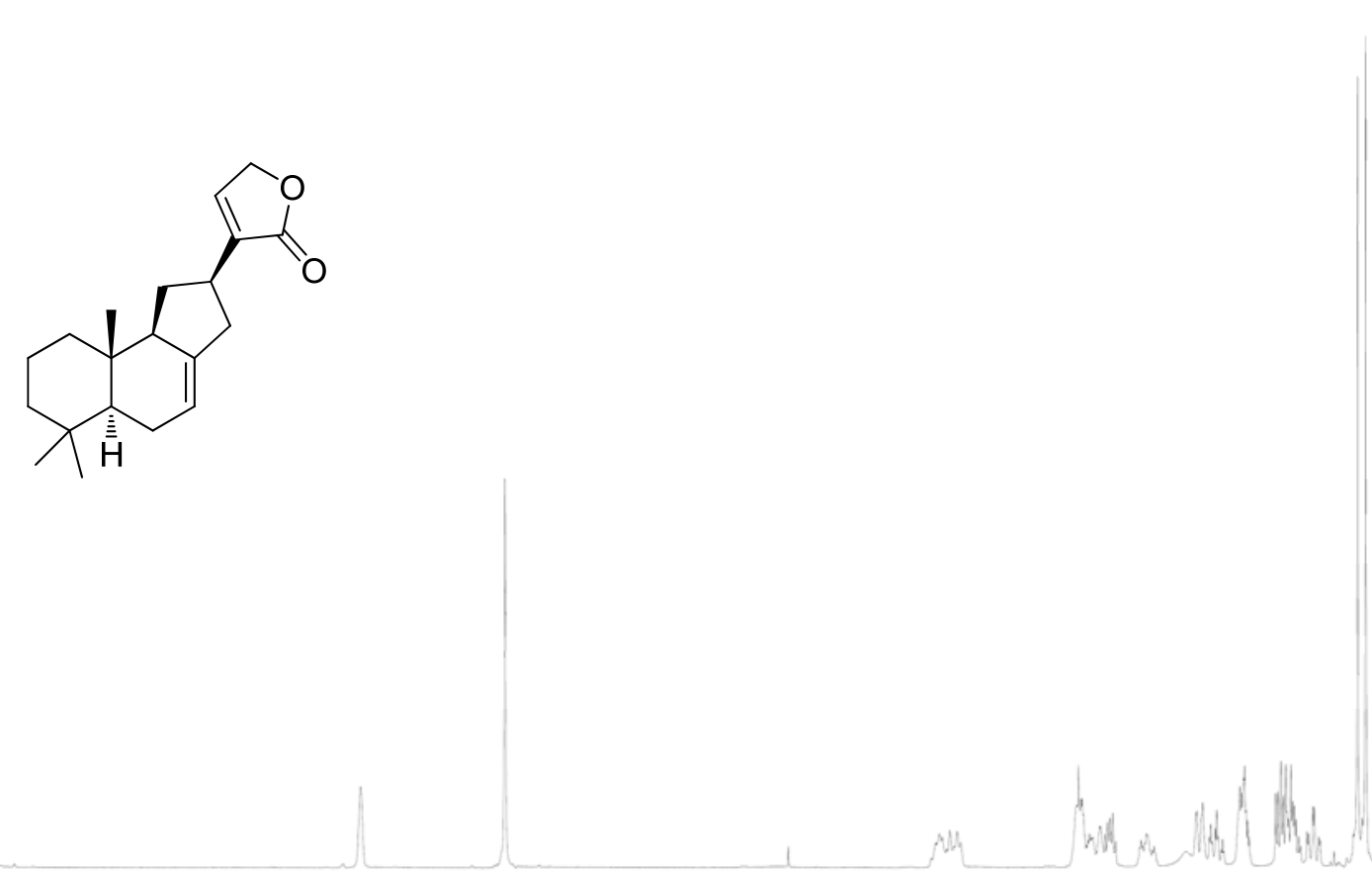

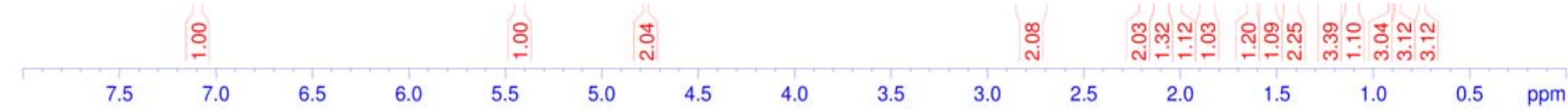

Figure S18. ${ }^{1} \mathrm{H}$ NMR spectrum of compound $3\left(500 \mathrm{MHz}, \mathrm{CDCl}_{3}\right)$ 
C-1325-5-Rz-16F1 in $\mathrm{CDCl} 3$

vrsc5908026001 (AV 500)

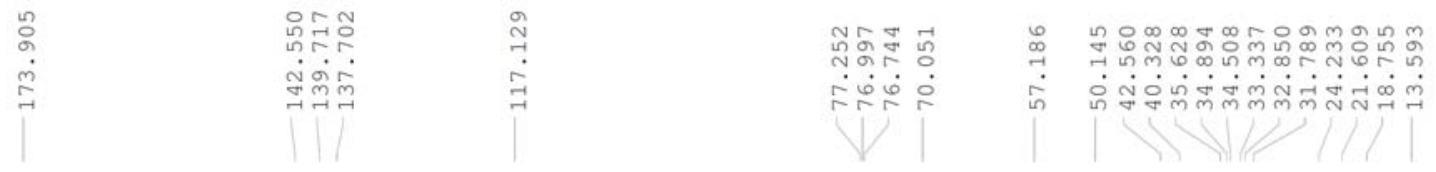

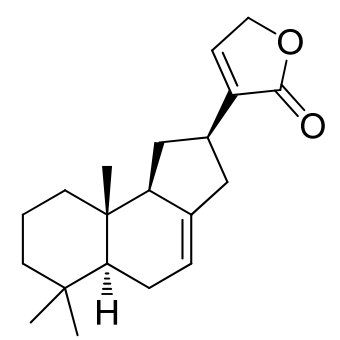

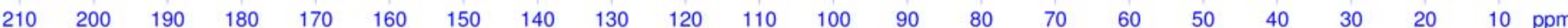

Figure S19. ${ }^{13} \mathrm{C}$ NMR spectrum of compound $3\left(125 \mathrm{MHz}, \mathrm{CDCl}_{3}\right)$ 


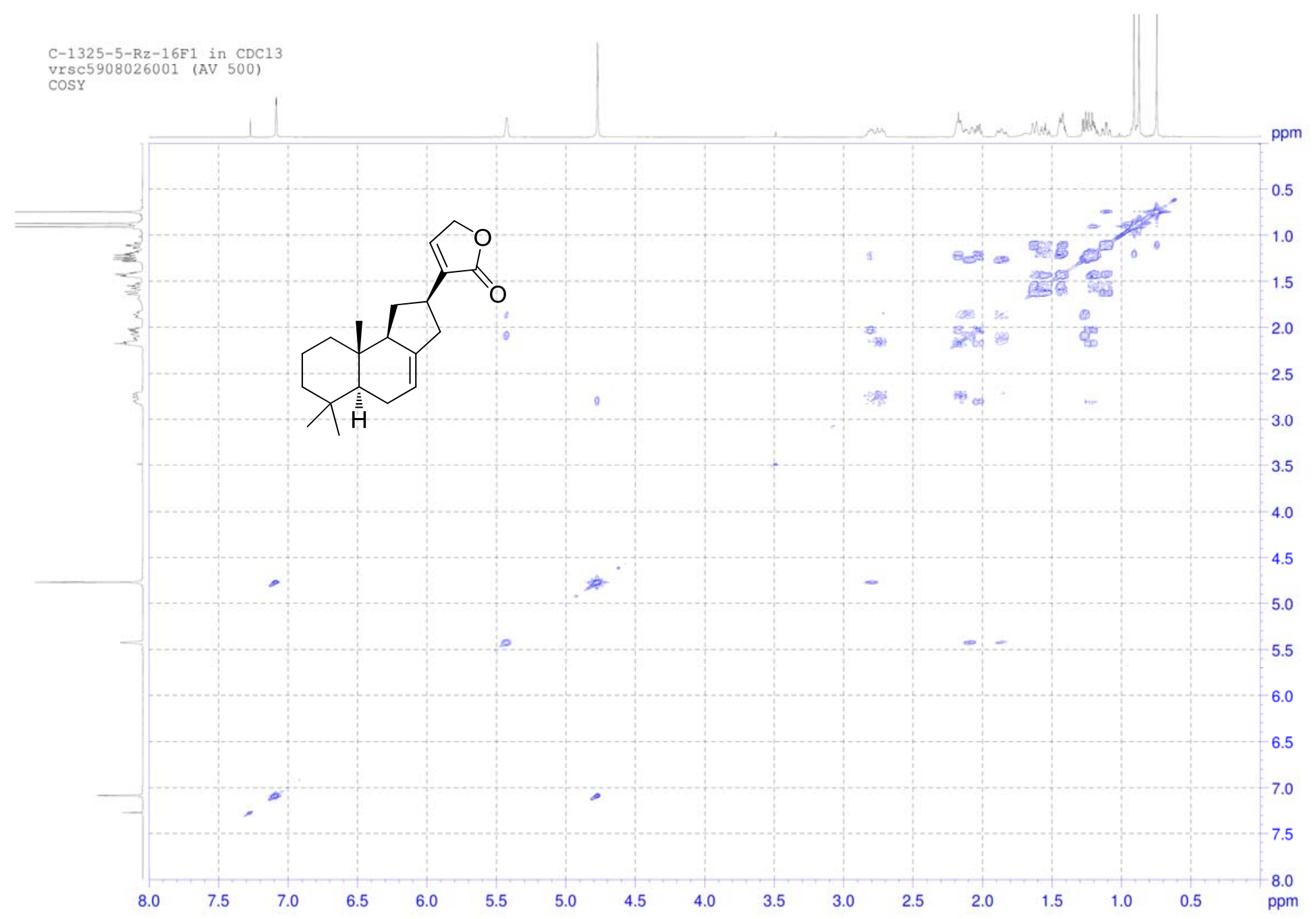

Figure S20. ${ }^{1} \mathrm{H}-{ }^{1} \mathrm{H}$ COSY data of compound $3\left(500 \mathrm{MHz}, \mathrm{CDCl}_{3}\right)$ 


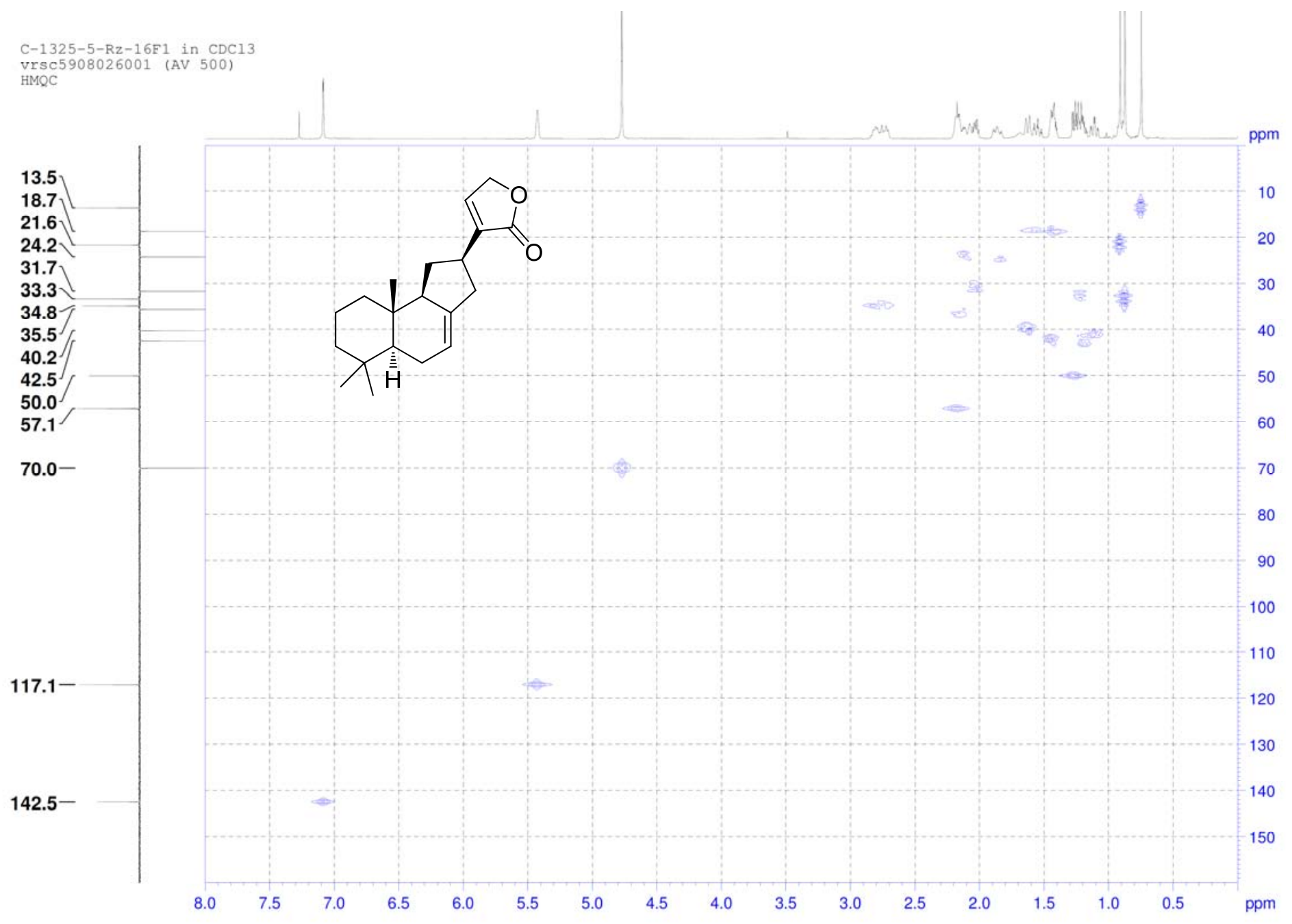

Figure S21. HMQC data of compound $3\left(500 \mathrm{MHz}, \mathrm{CDCl}_{3}\right)$ 


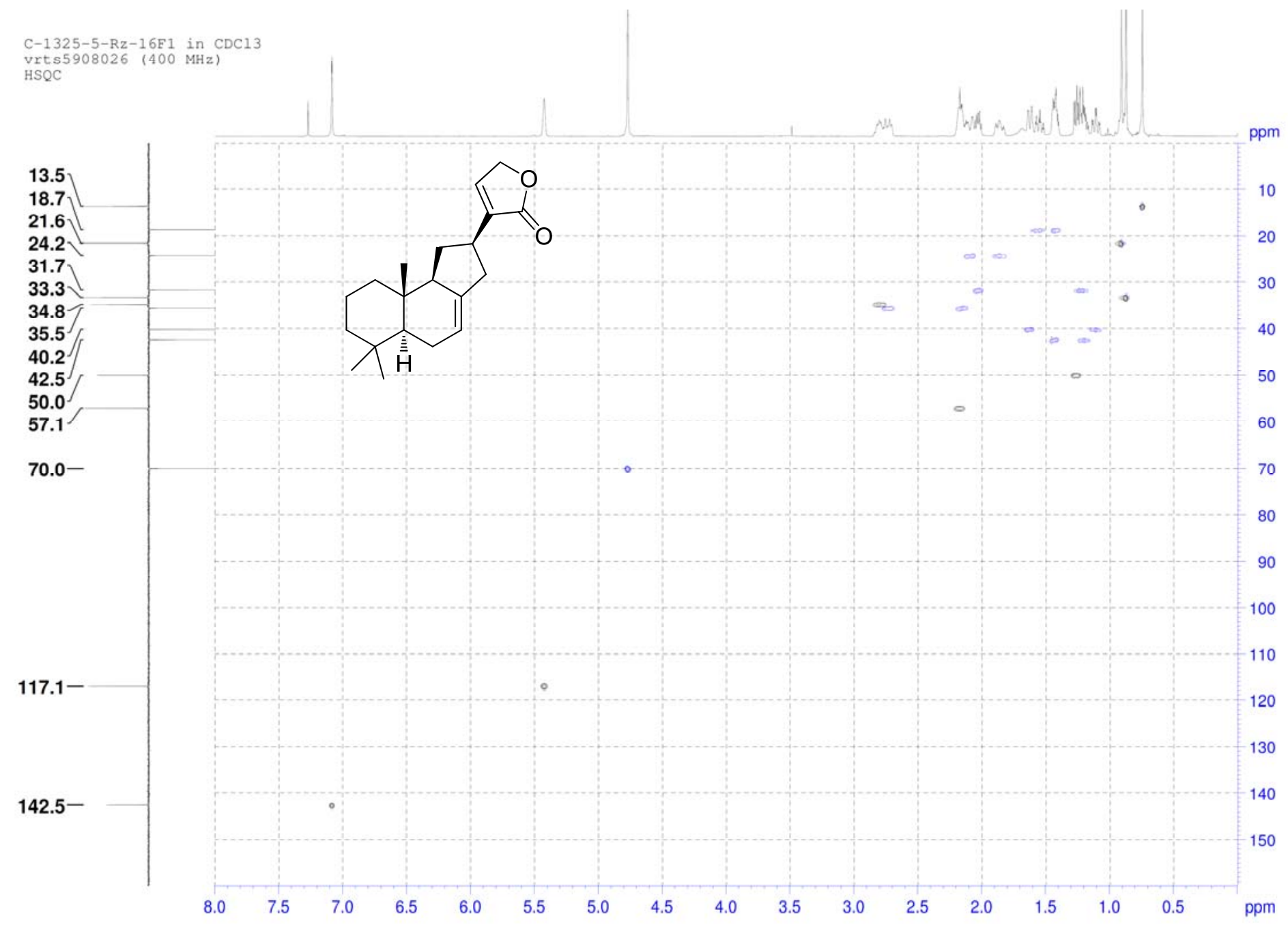

Figure S22. HSQC data of compound $3\left(400 \mathrm{MHz}, \mathrm{CDCl}_{3}\right)$ 


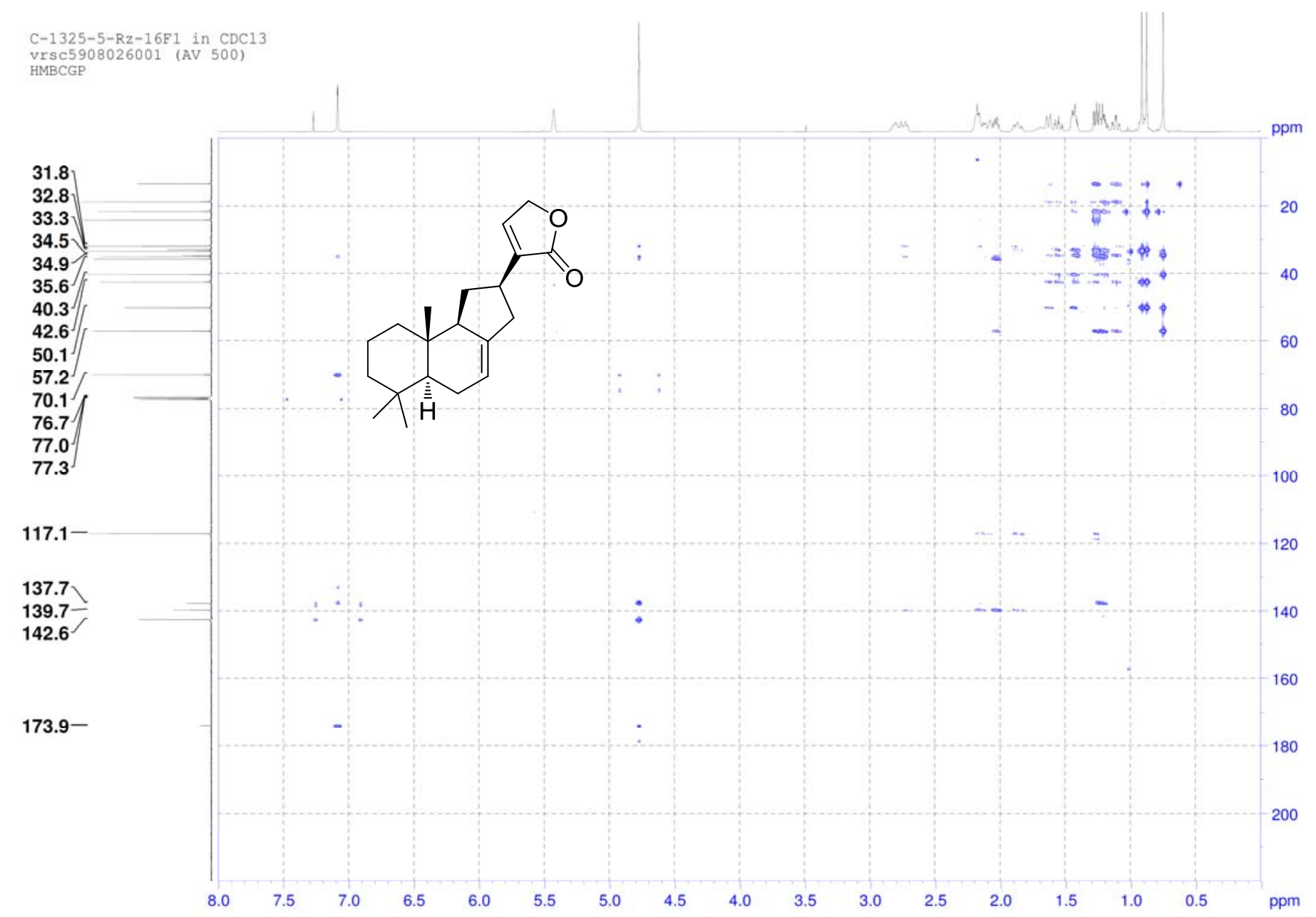

Figure S23. $\mathrm{HMBC}$ data of compound $3\left(500 \mathrm{MHz}, \mathrm{CDCl}_{3}\right)$ 


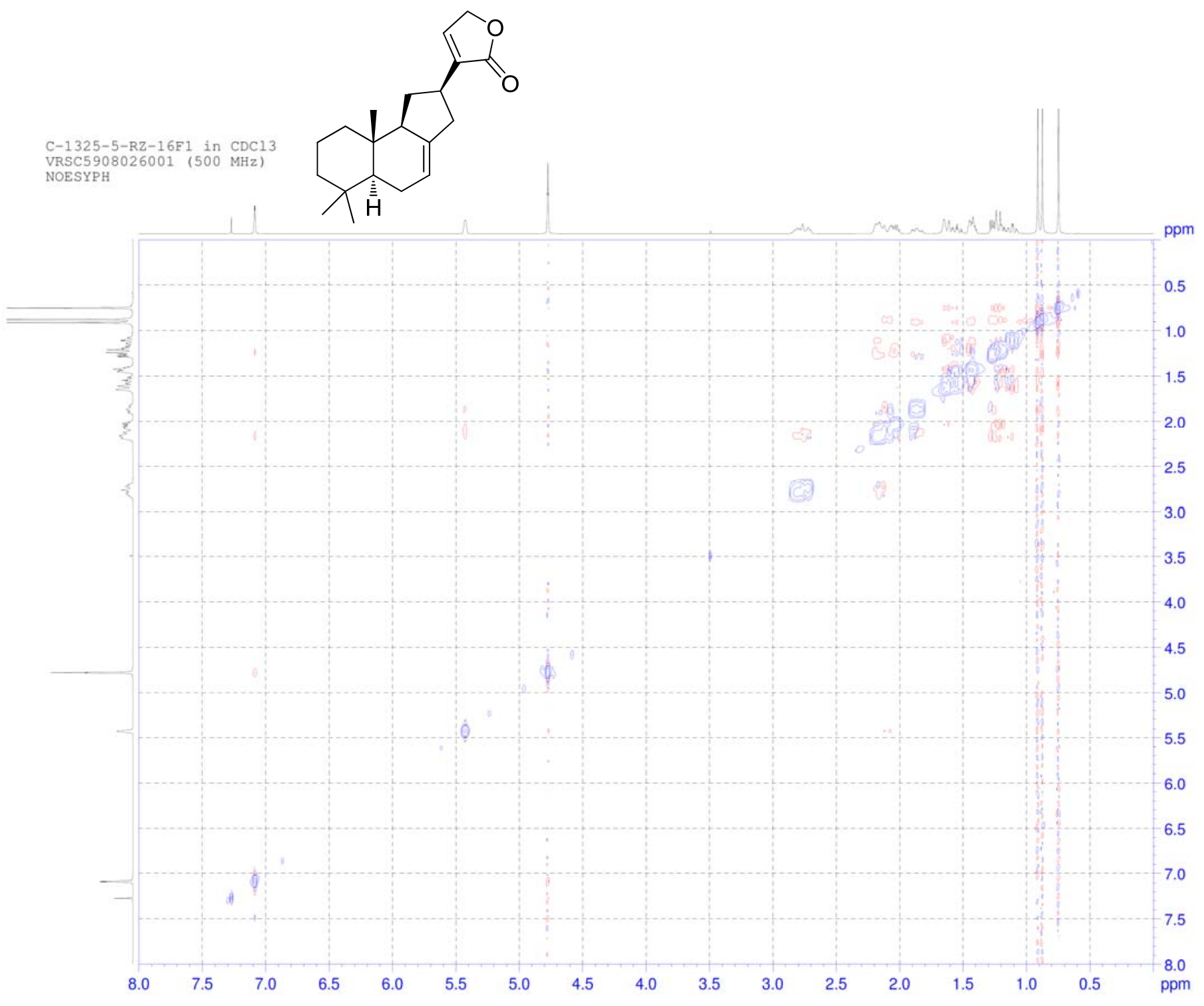

Figure S24. NOESY data of compound $3\left(500 \mathrm{MHz}, \mathrm{CDCl}_{3}\right)$ 


\section{Mass Spectrum List Report}

Analysis Info

Analysis Name VRTSM909013002.d

Method Tune_low_POS_13_09_16.m

Sample Name C-1325-5.Rz-16F1

Acquisition Date 9/13/2016 2:03:48 PM

Administrator

13-09-16

Instrument

micrOTOF

72

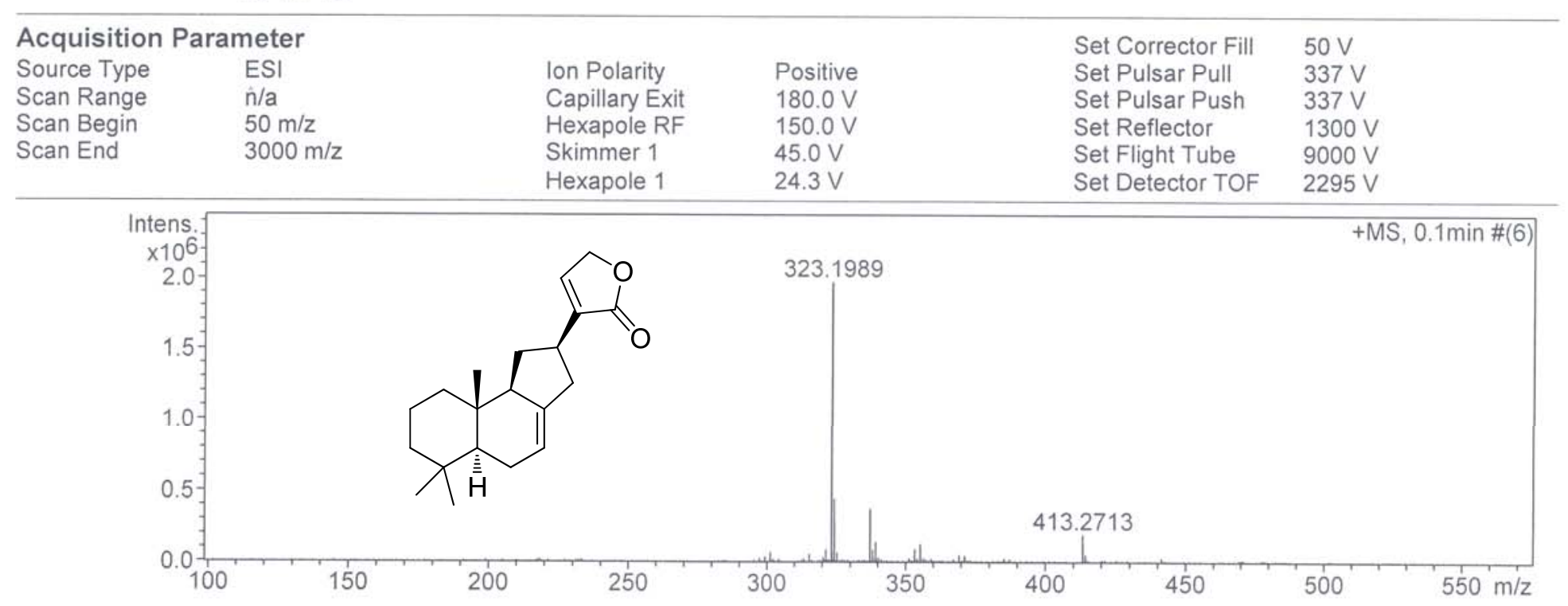

Figure S25. HRESIMS data of compound 3 